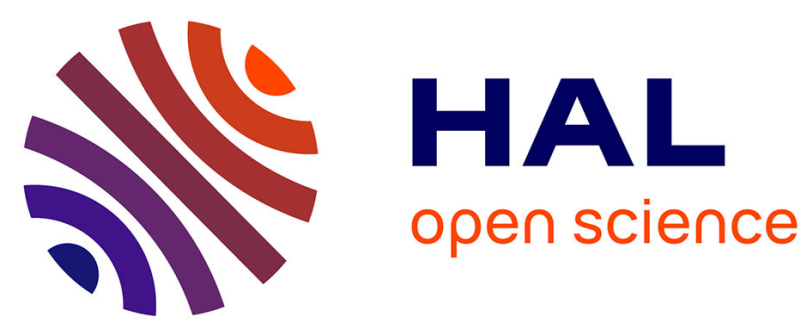

\title{
Increasing knowledge in IGF1R defects: lessons from 35 new patients
}

Eloïse Giabicani, Marjolaine Willems, Virginie Steunou, Sandra

Chantot-Bastaraud, Nathalie Thibaud, Walid Abi Habib, Salah Azzi, Bich

Lam, Laurence Bérard, Hélène Bony-Trifunovic, et al.

\section{To cite this version:}

Eloïse Giabicani, Marjolaine Willems, Virginie Steunou, Sandra Chantot-Bastaraud, Nathalie Thibaud, et al.. Increasing knowledge in IGF1R defects: lessons from 35 new patients. Journal of Medical Genetics, In press, 10.1136/jmedgenet-2019-106328 . hal-02435128

\section{HAL Id: hal-02435128 \\ https://hal.sorbonne-universite.fr/hal-02435128}

Submitted on 10 Jan 2020

HAL is a multi-disciplinary open access archive for the deposit and dissemination of scientific research documents, whether they are published or not. The documents may come from teaching and research institutions in France or abroad, or from public or private research centers.
L'archive ouverte pluridisciplinaire $\mathbf{H A L}$, est destinée au dépôt et à la diffusion de documents scientifiques de niveau recherche, publiés ou non, émanant des établissements d'enseignement et de recherche français ou étrangers, des laboratoires publics ou privés. 
2 Eloïse Giabicani ${ }^{1}$, Marjolaine Willems ${ }^{2,}$ Virginie Steunou ${ }^{1}$, Sandra Chantot-Bastaraud ${ }^{3}$, Nathalie Thibaud ${ }^{1}$,

3 Walid Abi Habib ${ }^{1}$, Salah Azzi ${ }^{1}$, Bich Lam ${ }^{1}$, Laurence Bérard ${ }^{1}$, Hélène Bony-Trifunovic ${ }^{4}$, Cécile Brachet ${ }^{5}$,

4 Elise Brischoux-Boucher ${ }^{6}$, Emmanuelle Caldagues ${ }^{7}$, Régis Coutant ${ }^{8}$, Marie-Laure Cuvelier ${ }^{9}$, Georges

5 Gelwane $^{10}$, Isabelle Guemas ${ }^{7}$, Muriel Houang ${ }^{1}$, Bertrand Isidor ${ }^{11}$, Claire Jeandel ${ }^{12}$, James Lespinasse ${ }^{13}$,

6 Catherine Naud-Saudreau ${ }^{14}$, Monique Jesuran-Perelroizen ${ }^{15,16}$, Laurence Perrin-Sabourin ${ }^{17}$, Juliette Piard ${ }^{6}$

7 Claire Sechter ${ }^{18}$, Pierre-François Souchon ${ }^{19}$, Caroline Storey ${ }^{10}$, Domitille Thomas ${ }^{1}$, Yves Le Bouc ${ }^{1}$, Sylvie

8 Rossignol $^{20,21}$, Irène Netchine ${ }^{1}$, and Frédéric Brioude ${ }^{1}$.

10 1. Sorbonne Université, INSERM, Centre de Recherche Saint Antoine, APHP, Hôpital Armand

11 Trousseau, Explorations Fonctionnelles Endocriniennes, F-75012, Paris, France.

12 2. CHU Arnaud de Villeneuve, Département de Génétique Médicale, 34000 Montpellier, France.

13 3. APHP, Hôpital Armand Trousseau, Département de Génétique, UF de Génétique Chromosomique, F-

1475012 , Paris, France.

15 4. CHU Amiens Picardie, Médecine Pédiatrique et Médecine de l'Adolescent, 80054 Amiens, France.

16 5. Hôpital Universitaire des Enfants Reine Fabiola, Université libre de Bruxelles, 1020 Bruxelles,

17 Belgium.

18 6. Université de Franche-Comté, CHRU Saint Jacques, Centre de Génétique Humaine, 25030 Besançon, 19 France.

20 7. CHU Nantes, Médecine Pédiatrique, 44000 Nantes, France.

21 8. CHU Angers, Endocrinologie et Diabétologie Pédiatriques, 49000Angers, France.

22 9. CH Calais, Pédiatrie, 62100 Calais, France.

23 10. Université Paris Diderot, APHP, Hôpital Robert Debré, Endocrinologie et Diabétologie Pédiatriques, 2475019 Paris, France.

25 11. CHU Nantes, Service de Génétique Médicale, 44000 Nantes, France. 
27 l'Adolescent, 34000 Montpellier, France.

28 13. CH Métropole Savoie, UF de Génétique Chromosomique, 73000 Chambéry, France.

29 14. CH Bretagne Sud, Endocrinologie et Diabétologie Pédiatriques, 56100 Lorient, France.

30 15. Cabinet libéral d'endocrinologie-pédiatrique, 14 rue du Rempart Saint Etienne, 31000 Toulouse, $31 \quad$ France.

32 16.AFPEL, 59800 Lille, France.

33 17. Université Paris Diderot, APHP, Hôpital Robert Debré, Unité de Génétique Clinique, 75019 Paris, $34 \quad$ France.

35 18. Université de Franche-Comté, CHU Jean Minjoz, Unité d'Endocrinologie et Diabétologie 36 Pédiatriques, 25030 Besançon, France.

37 19. CHU Reims, American Memorial Hospital, Diabétologie et Endocrinologie Pédiatriques, 51100 38 Reims, France.

39 20. Hôpitaux Universitaires de Strasbourg, Service de Pédiatrie, Strasbourg, France.

40 21. INSERM U1112, Laboratoire de Génétique Médicale, Institut de Génétique Médicale d'Alsace

41 (IGMA), Faculté de Médecine de Strasbourg, Strasbourg, France.

\section{Corresponding author:}

43 Eloïse Giabicani, MD

44 Explorations Fonctionnelles Endocriniennes, Hôpital Armand Trousseau

4526 avenue du Dr Arnold Netter, 75571 Paris cedex 12, France

46 Email : eloise.giabicani@aphp.fr, phone : +33171738032, fax : +33144736127

47

48 Keywords: IGF1R, IGF-I, AKT, fetal growth, intra-uterine growth retardation, small for gestational age,

49 Silver-Russell syndrome, haploinsufficiency, homozygous variant.

50 Word count: 4577 


\section{ABSTRACT}

52 (248words)

53 Background: The IGF1R is a keystone of fetal growth regulation by mediating the effects of IGF-I and

54 IGF-II. Recently, a cohort of patients carrying an IGFIR defect was described, from which a clinical score

55 was established for diagnosis. We assessed this score in a large cohort of patients with identified IGF1R

56 defects, as no external validation was available. Furthermore, we aimed to develop a functional test to

57 allow the classification of variants of unknown significance (VUS) in vitro.

58 Methods: DNA was tested for either deletions or single nucleotide variant (SNV) and the phosphorylation

59 of downstream pathways studied after stimulation with IGF-I by western blotting of fibroblast of nine

60 patients.

61 Results: We detected $21 I G F 1 R$ defects in 35 patients, including eight deletions and 10 heterozygous, one

62 homozygous, and one compound-heterozygous SNVs. The main clinical characteristics of these patients

63 were being born small for gestational age (90.9\%), short stature (88.2\%), and microcephaly $(74.1 \%)$.

64 Feeding difficulties and varying degrees of developmental delay were highly prevalent (54.5\%). There

65 were no differences in phenotypes between patients with deletions and SNVs of IGF1R. Functional

66 studies showed that the six missense SNVs tested were associated with decreased AKT phosphorylation.

67 Conclusion: We report eight new pathogenic variants of $I G F 1 R$ and an original case with a homozygous $\mathrm{SNV}$. We found the recently proposed clinical score to be accurate for the diagnosis of $I G F I R$ defects with a sensitivity of $95.2 \%$. We developed an efficient functional test to assess the pathogenicity of SNVs,

70 which is useful, especially for VUS. 
75 Insulin-like growth factors IGF-I and IGF-II are major factors which stimulate fetal growth. Both bind to

76 the type 1 IGF receptor (IGF1R). Binding of IGFs to this receptor leads to autophosphorylation of

77 intracellular tyrosine residues, which in turn leads to activation of the phosphatidyl-inositide 3-kinase

78 (PI3K)/AKT and mitogen-activated protein kinase (MAPK)/ERK signaling pathways, resulting in cellular

79 proliferation and growth [1]. IGF1R is located at chromosome $15 \mathrm{q} 26$, contains 21 exons, and leads to the

80 expression of a dimeric transmembrane tyrosine-kinase receptor (figure 1A. and 1C.) [2]. IGF1R and the

81 insulin receptor (IR) share more than 50\% homology and hybrid dimers can be generated, the function of

82 which is still unclear [3].

83 The first description of the involvement of $I G F 1 R$ defects in pre and post-natal growth failure was made

84 by Pasquali et al. in the late seventies [4]. The authors described patients with intra-uterine growth

85 retardation (IUGR), post-natal growth failure, and microcephaly due to a $15 \mathrm{q} 26$ terminal deletion that

86 included IGF1R (OMIM \#612626). Butler et al. then described a similar phenotype in patients with ring

87 chromosome 15 with $I G F 1 R$ deleted [5]. The phenotype-genotype correlation was unclear because of the

88 difference in gene content of these large deletions. In 2013, Abuzzahab et al. reported a loss of function of

89 the IGF1R in two children with either compound heterozygous pathogenic missense variants or a

90 heterozygous pathogenic nonsense variant of IGF1R (OMIM \#270450) [6]. Since then, many others have

91 reported pathogenic variants in $I G F 1 R$, mainly in the heterozygous state and rarely in the compound

92 heterozygous state $(n=3)$ [7 and references within]. Finally, in 2012, Gannagé-Yared et al. reported the

93 first patient with a homozygous pathogenic variant [8]. Most of the reported cases were born small for

94 gestational age (SGA) with no or poor catch-up growth, but the final heights are widely variable and can

95 be in the normal range. Indeed variable phenotypic expression has already been reported, even in relatives

96 carrying the same molecular defect, which makes the diagnosis of IGFIR defects difficult $[9,10]$.

97 Furthermore, some authors have highlighted that the phenotype of patients with IGF1R defects overlaps

98 with that of either Silver-Russell syndrome (SRS, OMIM \#180860) or SHORT syndrome (OMIM 

appears to be highly specific for IGFIR defects. Thus, the recent international consensus about SRS mentioned IGFIR defects as a differential diagnosis of SRS in case of absence of relative macrocephaly, meaning that head circumference should be assessed in a patient born SGA with poor catch-up growth to distinguish between these etiologies [13]. From the first descriptive cohort of 25 patients with IGF1R defects, Walenkamp et al. proposed a clinical score to drive molecular investigations [14]. This score combines the following four items: birth length or weight $<-1$ standard deviation score (SDS), head 106 circumference $<-2$ SDS at first presentation, height at first presentation $<-2.5$ SDS, and plasma IGF-I 107 levels above the mean for age and gender. Molecular testing for IGF1R should be proposed if three or 108 more items are present, with a sensitivity of $76 \%$ in their cohort [14]. Recently, Janchevska et al. 109 identified two anomalies of IGF1R in a cohort of 64 patients born SGA with no catch-up growth, 110 supporting the hypothesis that the prevalence of these defects is high enough to search for them in this 111 particular group of patients [15]. Concerning the treatment of postnatal short stature, the efficiency of 112 recombinant growth hormone (rGH) therapy in patients with $I G F 1 R$ defects is still controversial and only 113 isolated cases with variable age at onset, duration, and dose of treatment have been reported $[7,14]$.

114 A few functional studies in either fibroblasts or cell lines have been reported, generally showing the 115 inability of the mutated receptor to activate downstream pathways, especially phosphorylation of the 116 receptor itself and/or AKT and rarely ERK [15-18]. In 2009, Fang et al. demonstrated IGF1R 117 haploinsufficiency due to a mRNA decay phenomenon in a nonsense variant in exon 18 [10]. Most groups 118 have not observed any effect on the expression of the transmembrane IGF1R in patients with missense 119 variants $[6,10,19,20]$.

120 We report here a large cohort of $21 I G F I R$ defects, including eight previously unreported pathogenic 121 variants. Furthermore, we established phenotype-genotype correlations and assessed the efficiency of rGH 122 therapy in these patients. Finally, we developed a reproductive functional test to assess the responsibility 123 of variants of unknown significance (VUS) in the phenotype. 


\section{MATERIALS AND METHODS}

125

126

127

128

129

130

131

132

133

134

135

136

137

\section{Molecular analysis}

139 All molecular diagnosis of the IGF1R defects was performed in the same laboratory of molecular genetics.

140 DNA was extracted from blood leukocytes using an in-house protocol after cell lysis by a salting out

141 procedure, as previously described [23]. DNA was quantified using a NanoDrop ND-1000

142 Spectrophotometer (Invitrogen, France).

143 The main known molecular causes of SRS (loss of methylation at 11p15, maternal uniparental disomy of

144 chromosome 7) or Temple syndrome (OMIM\#616222) at the 14q32.2 locus were ruled out by methylation

145 analysis, as detailed in a previous study [23].

$146 I G F 1 R$ deletions were assessed by multiplex ligation-dependent probe amplification (MLPA) using the

147 SALSA MLPA P217 IGF1R probe mix (MRC Holland, Amsterdam, Netherlands), following the 

provided by MRC-Holland.

150 For single nucleotide polymorphism (SNP) microarray analysis, samples were processed using cytoSNP151 12, or HumanOmniExpress-24 microarrays (Illumina, San Diego, CA, USA). Automated Illumina 152 microarray experiments were performed according to the manufacturer's instructions. Images were 153 acquired using an iScan System (Illumina). Image analysis and automated CNV calling were performed 154 using GenomeStudio v.2011.1 and CNVPartition v.3.1.6. SNP profiles were analyzed by examination of 155 signal intensity (Log R ratio, i.e. ln (sample copy number/reference copy number)) and allelic composition 156 (BAF, i.e. B Allele Frequency).

157 For the detection of IGFIR SNV, DNA was amplified and sequenced by direct Sanger sequencing 158 procedures, using the ABI PRISM Big Dye Terminator v3.0 Cycle Sequencing Kit and an ABI 3100 159 Genetic Analyzer (Life Technologies, Courtaboeuf, France). Sequences were then analyzed with 160 SeqScape v2.6 (Life Technologies).

161 Variants are described in accordance with the recommendations of the Human Genome Variation Society. 162 All the new variants were recorded in the ClinVar database (https://www.ncbi.nlm.nih.gov/clinvar).

163 Variant interpretation was performed following the American College of Medical Genetics and Genomics 164 and the Association for Molecular Pathology (ACMG/AMP) classification of variants [24]. Six main 165 categories are evaluated according to these guidelines: population data (prevalence of the variant in control populations), computational in silico predictive data, functional characterization, segregation, de novo data and allelic data (e.g. variant detected in trans with a pathogenic variant for a recessive disorder). Depending on these data, variants are classified as benign or likely benign, pathogenic or likely pathogenic and some stay of uncertain significance. 
171 Patient fibroblasts, obtained from skin biopsies after informed consent and control fibroblasts obtained

172 from the Coriell Institute of Medical Research (Camden, N.J.), were cultured in Dulbecco's Modified

173 Eagle Medium enriched with glutamate, sodium pyruvate, penicillin, streptomycin, and $10 \%$ fetal-calf

174 serum at $37^{\circ} \mathrm{C}$. After $24 \mathrm{~h}$ of serum-free culture in six-well plates, cells were stimulated with [50 $\left.\mathrm{ng} / \mathrm{ml}\right]$

175 IGF-I (Peprotech, US) for $10 \mathrm{~min}$ before lysis. We found these stimulation conditions to be the most

176 accurate to assess both AKT and ERK phosphorylation in controls. For both non-stimulated and

177 stimulated conditions, 4.2 to $12.1 \mu \mathrm{g}$ of protein was deposited in a NuPAGE ${ }^{\mathrm{TM}} 4-12 \%$ Bis-Tris Gel

178 (Thermo Fischer Scientific, US). Electrophoresis was performed on an XCell SureLock ${ }^{\mathrm{TM}}$ Mini-Cell

179 Electrophoresis system (Thermo Fischer Scientific, US). Membranes were incubated with polyclonal 180 antibodies against either phospho-AKT (Ser473, Cell Signaling, US, 1:2000), pan-AKT (Cell Signaling, 181 1:1000), phospho-ERK1/2 (Tyr204, Cliniscience, France, 1:800), ERK1/2 (Cell Signaling, 1:1000), or 182 GAPDH for normalization (Cell Signaling, 1:2000). Then, membranes were incubated with an HRP183 conjugated secondary antirabbit antibody $(1: 3,000)$, revealed with ChemiDoc ${ }^{\mathrm{TM}}$ XRS + System (Bio-Rad, 184 US), and analyzed with Quantity One v4.6.6 software. Immunoblot images were quantified using ImageJ 1851.50 software (https://imagej.nih.gov).

mRNA quantification

188 Total mRNA was extracted from non-stimulated cells using NucleoSpin miRNA® (Macherey-Nagel) and 189 cDNA obtained by reverse-transcriptase polymerase chain reaction (RT-PCR, Superscript II, Invitrogen, 190 France). cDNA was then amplified and quantified on a QuantStudio 7 Flex Real-Time PCR system 191 (Thermo Fischer) using primers localized in exons 7-8 by SYBR Green technology (Applied Biosystem, 192 US).

\section{Biological assays}

194 IGF-I serum concentrations were determined by different techniques, as patients were followed in 195 different centers. However, IGF-I levels were collected along with the normal values (NV) for most 
patients. Thus, IGF-I levels were considered as high if $>1$ SDS according to the technique used. We

197 express IGF-I levels as SDS according to age and gender from control matched references [25].

\section{Statistical analysis}

199 Characteristics of the population are described as percentages for qualitative variables or as SDS and mean 200 (range) for continuous variables. For statistical analysis, Pearson's test was used for correlations, Fisher's 201 test for dichotomous variables, and the t-test for continuous variables.

\section{RESULTS}

\section{Genetic results}

204 Between 2006 and 2018, 111 samples of DNA were tested for IGF1R mutations/deletions. We identified 205 IGF1R defects in 35 patients from 20 different families. Aside from the 20 index cases, we identified $206 I G F 1 R$ defects in 15 relatives, including three siblings, seven fathers, and five mothers. Among the 20 207 index cases, molecular analysis was prescribed for 13 patients for a clinical suspicion of an IGFIR defect 208 and for seven for a clinical suspicion of SRS (Supplementary figure 1). The molecular diagnosis of the 209 IGFIR defect was made at 9.2 years of age (0.8 to 18.1) for the index cases. Eight patients carried a 210 heterozygous deletion (figure 1B.). Eleven carried a single nucleotide variant (SNV): 8 missense, two 211 nonsense, and one insertion at the boundary of intron 5-exon 6. Sequencing of the cDNA of the latter 212 variant obtained from lymphocytes confirmed that the inserted guanine was present in the cDNA, leading 213 to a frameshift and a premature stop codon (N417Efs*52, Supplementary figure 2). One patient carried 214 two missense SNVs. Among the 13 SNVs identified, 10 patients had a heterozygous SNV, one patient 215 had compound heterozygous missense SNV, and one carried a homozygous missense SNV (figure 1). 216 Parental DNA samples were available for 13 patients. Three inherited the anomaly from their mother, five 217 from their father, two from both parents, and the anomaly arose de novo for three patients. Among the 13 218 variants, we identified eight new pathogenic or likely pathogenic variants (Table 1). Five deletions 219 included the entire IGFIR gene, one interstitial and four terminal lengthening from 3.13 to $5.01 \mathrm{Mb}$ (figure 
220 1B., Del1 to 5), whereas three included only part of $I G F 1 R$ with length from $19 \mathrm{~kb}$ to $234 \mathrm{~kb}$ (figure $1 \mathrm{~B}$., 221 Del6 to 8).

\section{Clinical features}

223 The intragenic deletions (exon 2, Del6, $\mathrm{n}=3$ ) and $I G F 1 R$ terminal deletions (Del7, $\mathrm{n}=2$ and Del8, $\mathrm{n}=1$ )

224 did not include other disease-causing OMIM genes and were thus analyzed together with the SNVs for the 225 clinical study. Clinical characteristics are shown in Table 2. There was no statistical difference in clinical 226 presentation between patients with large deletions and pathogenic variants of IGF1R. We calculated the 227 clinical score recently proposed by Walenkamp et al. for 21 patients for whom clinical data required for 228 this scoring system were fully available (birth weight or length $<-1$ SDS, height at presentation $<-2.5$ 229 SDS, head circumference at presentation < -2 SDS (microcephaly) and IGF-I level > 0 SDS) [14]. Twenty 230 patients (95.2\%) met at least three of the four criteria and $11(52.4 \%)$ fulfilled all four. Among them, all 231 had a birth weight or length $<-1$ SDS, 17 (81.0\%) had a height at presentation below -2.5 SDS, and 19 232 (90.5\%) had microcephaly. All 21 patients scored positive for elevated IGF-1 levels if considered at the 233 different endpoints (including during rGH treatment). However, five patients (23.8\%) would have not met 234 this criterion if IGF-I levels were considered only prior to the initiation of rGH treatment. One patient 235 (carrying Del6) did not achieve a positive clinical score, with only two items [being born with a height or 236 weight $<-1$ SDS and high levels of IGF-I (during rGH treatment only)].

237 Given the clinical overlap between SRS and IGFIR defects, the Netchine-Harbison clinical scoring 238 system (with a positive clinical diagnosis of SRS for a score of at least 4/6) was assessable for 10 patients 239 and only one scored 4/6 [13,26] (lacking relative macrocephaly at birth and body asymmetry items). 240 Nevertheless, most patients scored 3 out of 6, comprising the following items: being born SGA, post-natal 241 growth retardation, and feeding difficulties. 


\begin{tabular}{|c|c|c|c|c|c|c|}
\hline \multicolumn{7}{|c|}{ ACMP/AMP } \\
\hline $\begin{array}{c}\text { cDNA nomenclature } \\
\text { NM_000875.4 }\end{array}$ & Reference & $\begin{array}{c}\text { Amino-acid } \\
\text { substitution } \\
\text { NP_000866.1 }\end{array}$ & ClinVar & GnomAD & Detailed staging & $\begin{array}{c}\text { Variant } \\
\text { classification\# }\end{array}$ \\
\hline c. $118 \mathrm{C}>\mathrm{T}$ & This study & $\mathrm{R} 40 \mathrm{C}$ & SCV000926288 & Not reported & PM1 PM2 PP2 PP3 & Likely pathogenic \\
\hline c. $384 \mathrm{~T}>\mathrm{C}$ & This study & F112L & SCV000926289 & Not reported & PS4 PM1 PM2 PP1 PP2 PP3 PS3 & Pathogenic \\
\hline c. $904 \mathrm{G}>\mathrm{T}$ & This study & $\mathrm{E} 302 *$ & SCV000926290 & Not reported & PVS1 PM2 PP3 PP4 & Pathogenic \\
\hline c. $995 \mathrm{G}>\mathrm{A}$ & This study & $\mathrm{C} 332 \mathrm{Y}$ & SCV000926291 & Not reported & PM1 PM2 PP2 PP3 BS4 & Likely pathogenic \\
\hline c. $1247+1-1247+2 \mathrm{insG}$ & This study & N417Efs*52 & SCV000926292 & Not reported & PS3 PM2 PM4 PP1 PP4 & Pathogenic \\
\hline c. $3162 \mathrm{G}>\mathrm{A}$ & This study & M1054I & SCV000926293 & Not reported & PM1 PM2 PP2 PP3 PP4 & Likely pathogenic \\
\hline c. $3454 \mathrm{G}>\mathrm{A}$ & This study & G1152R & SCV000926294 & Not reported & PS4 PM1 PM2 PP1 PP2 PP3 PP4 & Pathogenic \\
\hline c. $3539 \mathrm{C}>\mathrm{A}$ & This study & S1180Y & SCV000926295 & Not reported & PS4 PM1 PM2 PP2 PP1 PP3 & Pathogenic \\
\hline c. $2629 \mathrm{C}>\mathrm{T}$ & {$[30]$} & $\mathrm{R} 877^{*}$ & rs150221450 & AF: $3.977 .10^{-6}$ & PVS1 PM2 PP3 PP4 & Pathogenic \\
\hline c. $3530 \mathrm{G}>\mathrm{A}$ & {$[14]$} & $\mathrm{R} 1177 \mathrm{H}$ & SCV000926296 & Not reported $\S$ & PM1 PM2 PP2 PP3 & Likely pathogenic \\
\hline c. $3595 \mathrm{G}>\mathrm{A}$ & $\begin{array}{l}\text { EGL Genetic } \\
\text { Diagnostics }\end{array}$ & G1199R & rs886044448 & Not reported & PS4 PM1 PM2 PP1 PP2 PP3 PP4 & Pathogenic \\
\hline c. $4055 \mathrm{G}>\mathrm{T}$ & $\mathrm{dbSNP}$ & G1352V & rs759808066 & AF: $1.607 .10^{-5}$ & PM2 PP2 PP3 PS3 BS4 & Likely pathogenica \\
\hline c. $4066 \mathrm{G}>\mathrm{A}$ & [14] & E1356K & rs746562843 & AF: $642.10^{-5}$ & PM2 PP2 BS4 PS3 & Likely pathogenica \\
\hline
\end{tabular}

242

243 Table 1 


\begin{tabular}{|c|c|c|c|c|c|c|c|c|c|c|}
\hline & \multicolumn{3}{|c|}{ All $n=35$} & \multicolumn{3}{|c|}{ Deletions $n=6$} & \multicolumn{3}{|c|}{ SNVs $n=29$} & \multirow{3}{*}{$\begin{array}{c}\mathbf{p} \\
0.68\end{array}$} \\
\hline & Mean & Range & $\mathrm{n}(\%)$ & Mean & Range & n $(\%)$ & Mean & Range & n $(\%)$ & \\
\hline Sex (Female/Male) & & & $15 / 20$ & & & $2 / 4$ & & & $13 / 16$ & \\
\hline \multicolumn{11}{|l|}{ Birth parameters: } \\
\hline Term $($ WA $)$ & 37.7 & $31.0 ; 41.5$ & 23 & 38.4 & $37.0 ; 40.0$ & 5 & 37.5 & $31.0 ; 41.5$ & 18 & 0.82 \\
\hline Preterm $(<37$ WA $)$ & & & $5 / 23(21.7)$ & & & $0 / 5(0)$ & & & $5 / 18(27.8)$ & 0.55 \\
\hline Weight (SDS) & -2.5 & $-3.8 ;-1$ & 23 & -2.3 & $-3.2 ;-1.4$ & 5 & -2.5 & $-3.8 ;-1.0$ & 18 & 0.58 \\
\hline SGA \#(weight <- 2 SDS) & & & $17 / 23(73.9)$ & & & $3 / 5(60.0)$ & & & $14 / 18(77.8)$ & 1 \\
\hline Length (SDS) & -3.3 & $-5.2 ;-1.4$ & 22 & -3.0 & $-4.2 ;-2$ & 5 & -3.4 & $-5.2 ;-1.4$ & 17 & 0.46 \\
\hline SGA \# (length < -2 SDS) & & & 20/22 (90.9) & & & $4 / 5(80.0)$ & & & $16 / 17(94.1)$ & 1 \\
\hline Head circumference (SDS) & -2.6 & $-3.9 ;-0.3$ & 17 & -2.4 & $-3.0 ;-1.6$ & 5 & -2.7 & $-3.9 ;-0.3$ & 12 & 0.63 \\
\hline Microcephaly $(\mathrm{HC}<-2$ SDS $)$ & & & $14 / 17(82.4)$ & & & $4 / 5(80.0)$ & & & $10 / 12(83.3)$ & 1 \\
\hline Relative macrocephaly\# & & & $3 / 17(17.6)$ & & & $1 / 5(20.0)$ & & & $2 / 12(16.7)$ & 1 \\
\hline \multicolumn{11}{|l|}{ Clinical features: } \\
\hline Microcephaly & & & $20 / 27(74.1)$ & & & $4 / 4(100)$ & & & $16 / 23(69.6)$ & 0.70 \\
\hline Feeding difficulties\# & & & $12 / 22(54.5)$ & & & $4 / 5(80.0)$ & & & $8 / 17(47.1)$ & 0.69 \\
\hline Anorexia/thinness & & & $11 / 14(78.5)$ & & & $4 / 4(100.0)$ & & & $7 / 10(70.0)$ & 1.0 \\
\hline Enteral nutrition & & & $5 / 14(35.7)$ & & & $2 / 4(50.0)$ & & & $3 / 10(30.0)$ & 1 \\
\hline Developmental delay & & & $12 / 22(54.5)$ & & & $4 / 5(80.0)$ & & & $8 / 17(47.1)$ & 0.69 \\
\hline Language & & & $6 / 22(27.3)$ & & & $3 / 5(60.0)$ & & & $3 / 17(17.6)$ & 0.31 \\
\hline Motor & & & $6 / 22(27.3)$ & & & $1 / 5(20.0)$ & & & $5 / 17(29.4)$ & 1 \\
\hline Cognitive & & & $12 / 22(54.5)$ & & & $4 / 5(80.0)$ & & & $8 / 17(47.1)$ & 0.69 \\
\hline Assistance in school & & & $14 / 23(60.9)$ & & & $4 / 5(80.0)$ & & & $10 / 18(55.6)$ & 0.70 \\
\hline \multicolumn{11}{|l|}{ Clinical score ([14]): } \\
\hline Birth weight or length $<-1$ SDS & & & $21 / 21(100)$ & & & 4/4 (100) & & & $17 / 17(100)$ & \\
\hline Microcephaly $(\mathrm{HC}<-2$ SDS $)$ & & & $19 / 21(90.5)$ & & & $4 / 4(100)$ & & & $15 / 17(88.2)$ & \\
\hline Height \# $(<-2.5$ SDS $)$ & & & $17 / 21(81.0)$ & & & $4 / 4(100)$ & & & $13 / 17(76.5)$ & \\
\hline IGF-I $>0$ SDS & & & $21 / 21(100)$ & & & $4 / 4(100)$ & & & $17 / 17(100)$ & \\
\hline Final height (SDS): & -2.5 & $-4.2 ; 1.0$ & 25 & -2.9 & $-4.1 ;-2.1$ & 5 & -2.3 & $-4.2 ; 1.0$ & 20 & 0.30 \\
\hline Without rGH & -2.2 & $-4.2 ; 1.0$ & 13 & -3.2 & $-4.1 ;-2.1$ & 2 & -2.0 & $-4.2 ; 1.0$ & 11 & 0.42 \\
\hline With rGH & -2.8 & $-4.2 ;-1.0$ & 12 & -2.8 & $-3.8 ;-2.1$ & 3 & -2.8 & $-4.2 ;-1.0$ & 9 & 0.99 \\
\hline Short stature $(<-2$ SDS $)$ & & & $19 / 25(76.0)$ & & & $5 / 5(100)$ & & & $14 / 19(73.7)$ & 0.72 \\
\hline
\end{tabular}


245 No deafness was reported in our cohort. One girl (carrying a missense SNV) had a slightly delayed onset 246 of puberty (onset at 13.3 years), whereas the onset of puberty of the other 16 patients (10 boys) occurred at 247 the normal age. Three patients were treated with GnRH analogs together with rGH at the onset of puberty 248 to preserve the duration of growth due to a low predicted final height, despite the onset of puberty at a 249 normal age. Four patients carrying a missense SNV had attention deficit hyperactivity disorder (ADHD), 250 which required medication. Three patients developed obesity in childhood with metabolic syndrome for 251 one as a young adult. One patient (father of two affected children) had early type 2 diabetes and one 252 patient had episodes of hypoglycemia in infancy. Noticeably, four patients (two with IGFIR deletion, two 253 with a missense SNV) had cardiac defects, including one case of transient inter-auricular communication 254 (IAC), one of IAC and rhythmic troubles, one of patent foramen ovale, and one of severe cardiac 255 insufficiency, which led to heart transplantation (carrying a missense SNV).

256 Only two cases of homozygous pathogenic variants have yet been reported $[8,12]$. Thus, the pedigree and 257 growth curves of the girl with the F112L homozygous pathogenic variant are shown in figure 2. Although 258 the girl with the homozygous pathogenic variant (II.4) showed severe growth retardation of approximately $259-4$ SDS with tremendously elevated IGF-I [621 ng/mL (NV 20-300) at 1.6 years] and IGFBP-3 [5605 $260 \mathrm{ng} / \mathrm{mL}(\mathrm{NV}$ 800-3700)], both parents (I.1 and I.2) and one older sister (II.3) with the heterozygous 261 pathogenic variant showed impaired postnatal growth of approximately -2 SDS, with a final height in the 262 lower range of normal curves. The unaffected younger siblings (II.1 and II.2) showed normal growth 263 around the mean. Furthermore, the homozygous carrier (II.4) had a patent foramen ovale, severe oeso264 gastric reflux, anorexia requiring enteral support for one year (naso-gastric tube), and psychomotor delay 265 with learning disability, whereas no other member of the family presented with such clinical features.

266 All clinical data are available for each patient in Supplementary Table 1. 
268 Eighteen patients received $\mathrm{rGH}$ treatment, starting at an age of 7.5 years $(1.5 ; 15.3)$ under the SGA 269 European Medicines Agency (EMA) indication, with a mean height at the start of therapy of -3.8 SDS ($2705.6 ;-1.6)$. The starting dose was $46.6 \mu \mathrm{g} / \mathrm{kg} /$ day $(35.0 ; 85.5)$ and was significantly increased for only five 271 of the 15 patients for whom data on the dose evolution was available. For most patients $(60.0 \%)$, the dose 272 of rGH was not raised because of high serum levels of IGF-I. Among the 12 patients that completed rGH 273 treatment and reached their final height, the mean height gain was 1.0 SDS $(0.2 ; 2.5)$, which positively 274 correlated with the duration of treatment $(\rho=0.76, p=0.004)$ and negatively correlated with the age at the 275 start of $\mathrm{rGH}(\rho=-0.68, \mathrm{p}=0.01)$. IGF-I serum levels were high (over 1 SDS) for $11(47.8 \%)$ patients 276 before any treatment, with a mean of 1.9 SDS $(-2.0 ; 7.1)$, which rose to 3.3 SDS $(0.3 ; 9.5)$ under rGH 277 therapy.

\section{IGF1R functional test}

279 We performed functional analysis on fibroblasts for seven index cases, two affected parents and four controls (figure 3). The six missense SNVs all showed a decrease in phosphorylated AKT, although the results for the S1180Y variant did not reach statistical significance $(\mathrm{p}=0.065)$. Both $\mathrm{G} 1352 \mathrm{~V}$ and E1356K were predicted as VUS after in silico analysis and showed a significant decrease in AKT phosphorylation in vitro $(\mathrm{p}=0.009$ and $\mathrm{p}=0.002$, respectively), suggesting that these variants are likely pathogenic. There were no alterations of AKT phosphorylation for two patients carrying either a nonsense SNV or a chromosome $15 \mathrm{q} 26.6$ deletion that included the entire IGFIR gene. The results concerning ERK phosphorylation were highly variable and we observed no significant modifications in this pathway

287 (Supplementary figure 3). All but one patient showed normal IGF1R expression. This patient, who carries 288 a 15q26.6 heterozygous deletion, including IGF1R, showed expression of $37.7 \%$ of controls 289 (Supplementary figure 4). 


\section{DISCUSSION}

291 We report a large cohort of patients carrying various $I G F 1 R$ defects and describe eight new pathogenic 292 variants. Furthermore, we developed an in vitro functional test to assess the pathogenic impact of VUS.

293 As previously described, IGFIR defects are mainly present in the heterozygous state. Nevertheless, we 294 found two patients with missense SNVs on both alleles, including one patient with compound 295 heterozygous pathogenic variants and one with a homozygous one. The patient carrying the compound 296 heterozygous SNVs did not phenotypically differ from the other patients although both variants were 297 pathogenic. On the other hand, the homozygous pathogenic variant was associated with a more severe 298 phenotype in terms of growth, microcephaly, and mental retardation relative to that of her relatives who 299 carry the same variant in the heterozygous state.

300 With the advent of next-generation sequencing (including exome sequencing or a gene panel of growth 301 disorders, microcephaly, or cognitive impairment, which can include $I G F 1 R$ ), the identification of SNVs 302 will increase in the future. Thus, the description and registration of new SNVs with a precise phenotypic 303 description is necessary to distinguish between those that are benign and those that are pathogenic. 304 Furthermore, we demonstrated that functional characterization of such SNVs is sometimes necessary. In 305 our cohort, such experiments were helpful for the classification of two SNVs reported as SNPs with a very 306 low allele frequency and classified as VUS based on the ACMG/AMP recommendations because of 307 incomplete penetrance (E1356K and G1352V) [24]. However, the definition of "unaffected" carrier was 308 only based on the reported final heights of the two fathers who carried the variants, as other criteria were 309 not available (birth parameters, head circumference and IGF-I levels).Those two variants were finally 310 classified as likely to be pathogenic after demonstration of their functional consequences.

311 The in vitro studies showed impairment in the ability to activate downstream pathways for the receptors 312 affected by missense SNVs, especially the AKT pathway. We were unable to demonstrate any significant 313 functional consequences of deletions or nonsense SNV, unlike previous studies [10,27,28]. It is possible 314 that discrepancies between our results on deletions and those of previous studies may be due to different 
315 IGF-I concentrations used for stimulation. Indeed, Choi et al. showed a progressive increase in AKT 316 phosphorylation in fibroblasts from a patient with an IGFIR deletion in response to increasing IGF-I 317 concentrations from 1 to $400 \mathrm{ng} / \mathrm{mL}$ [28]. Ester et al. reported the same pattern with lower concentrations 318 (5 to $20 \mathrm{ng} / \mathrm{mL}$ ) [18]. Thus, it is possible that the IGF-I concentration we used (50 ng/mL) did not allow 319 proper discrimination of AKT phosphorylation between deletions and controls [29]. Nevertheless, the aim 320 of this functional study was to assess pathogenic impact of SNVs of unknown significance, and we found 321 IGF-I concentration of $50 \mathrm{ng} / \mathrm{mL}$ to be effective. Unlike missense pathogenic variants, which may lead to 322 a dominant-negative effect, deletions or nonsense variants may lead to haploinsufficiency. Although we 323 could not quantify membrane IGF1R, we demonstrated that IGF1R mRNA levels were low in fibroblasts 324 from one patient with a deletion, favoring haploinsufficiency [10,28,30].

325 Very recently, a scoring system has been proposed for a clinical suspicion of an IGF1R defect [14]. This 326 clinical score showed $95.2 \%$ sensitivity for our cohort. All patients were born with weight or length $<-1$ 327 SDS and microcephaly was almost always present. However, post-natal short stature (with a threshold set 328 at -2.5 SDS) was inconstantly observed in our cohort. However, height at first evaluation was usually 329 below -2 SDS. The clinical scoring system could be adapted for this item, so as not to miss patients with $330 I G F 1 R$ defects for whom height is not severely affected but this will result in an increased number of 331 patients that should be tested and thus, to a reduced specificity. Elevated circulating IGF-I levels were 332 absent prior to rGH therapy for $23.8 \%$ of the patients in our cohort but IGF-I levels rose markedly after 333 initiating rGH treatment. The absence of high IGF-I levels prior to rGH therapy can be explained by the 334 previously described feeding difficulties of some patients with IGFIR defects, which can lead to 335 nutritional deficiency and low basal levels of IGF-I [31]. This pattern of low IGF-I levels which increase 336 rapidly after initiating rGH therapy, should alert clinicians to the possibility of an IGF1R defect in a child 337 born SGA, especially with the presence of microcephaly. However, the high sensitivity of this clinical 338 score favors its use in routine diagnosis to drive genetic tests. The specificity of this clinical score should 339 be assessed in large cohorts of SGA patients with the help of molecular studies, as well as in patients with 
340 idiopathic short stature since fetal growth restriction, although highly prevalent, is not constant in patients 341 carrying IGF1R defect.

342 This cohort allowed us to better characterize the phenotype of patients with an IGFIR defect. As 343 previously described, fetal and post-natal growth retardation, microcephaly, and elevated IGF-I serum 344 levels were highly prevalent in our cohort $[7,14]$. As in previously reported cases, we identified several 345 cardiac anomalies in these patients, mostly benign. However, one patient underwent heart transplantation 346 because of severe cardiac failure. These findings are in accordance with previous observations and argue 347 in favor of a systematic cardiac ultrasound evaluation when an IGF1R defect is identified $[8,12,19,32]$. 348 Another interesting feature of our cohort is the presence of ADHD in several patients, which was only 349 been previously reported for one case [29]. Furthermore, as reported in the Dutch cohort, we found a high 350 prevalence of feeding difficulties, sometimes requiring nutritional support, $[9,11,14]$. This latter feature 351 may have misled some clinicians to consider a clinical diagnosis of SRS at first evaluation. Indeed patients 352 with SRS or IGF1R defects share several symptoms, including being born SGA, post-natal growth 353 retardation, and high circulating levels of IGF-I [33,34]. However patients with IGF1R defects usually 354 present with microcephaly, which distinguishes them from SRS patients, for whom head circumference is 355 relatively preserved at birth $[13,26]$. The recent international consensus on the diagnosis and management 356 of SRS stated that IGFIR defects represents a differential diagnosis and may be considered easily after the 357 major molecular defects of SRS are ruled out, especially for those patients with no relative macrocephaly $358[13]$.

359 The efficiency of rGH therapy in this cohort is difficult to ascertain, as this was a retrospective and 360 multicentric analysis with varying management in terms of the age at onset, the initial dose, dose 361 adaptation, and discontinuation of treatment. Since the duration and age at the start of treatment 362 significantly correlate with height gain, rGH treatment should be considered for patients with no catch-up 363 growth at four years of age, under the EMA SGA indication. However, both clinicians and patients (or 364 parents) should be aware of this unpredictable response to rGH therapy. Our in vitro experiments, 
accounting for the functional consequences of the variants, were unable to distinguish between those

IGF1R signalization is impaired. These high IGF-I levels raised concern on potentially negative long term allows us to consider these levels only as a consequence of IGF-I resistance. Thus, IGF-I levels should not be interpreted and used in patients with $I G F 1 R$ defects in the same manner as in unaffected patients. developed a functional test to assess IGF1R activity in vitro that is useful for sorting VUS, which is of particular importance, especially for accurate genetic counseling.

AKNOWLEDGEMENTS: We want to thank the patients and their families for their participation in the study. We also want to thank Pr Juliane Léger and Dr Hervé Testard for their collaboration, Mrs Marieexperiments.

\section{REFERENCES}

3831 Klammt J, Pfäffle R, Werner H, Kiess W. IGF signaling defects as causes of growth failure and 384 IUGR. Trends Endocrinol Metab TEM 2008;19:197-205.

3852 LeRoith D, Werner H, Beitner-Johnson D, Roberts CT. Molecular and cellular aspects of the 386 insulin-like growth factor I receptor. Endocr Rev 1995;16:143-63.

3873 Cai W, Sakaguchi M, Kleinridders A, Gonzalez-Del Pino G, Dreyfuss JM, O’Neill BT, Ramirez 388 AK, Pan H, Winnay JN, Boucher J, Eck MJ, Kahn CR. Domain-dependent effects of insulin and IGF-1 receptors on signalling and gene expression. Nat Commun 2017;8:14892.

3904 Pasquali F, Zuffardi O, Severi F, Colombo A, Burgio GR. Tandem translocation 15-13. Ann 391 Genet 1973;16:47-50. 

patients with ring chromosome 15 syndrome. Am J Med Genet 1988;29:149-54.

3946 Abuzzahab MJ, Schneider A, Goddard A, Grigorescu F, Lautier C, Keller E, Kiess W, Klammt J, 395 Kratzsch J, Osgood D, Pfäffle R, Raile K, Seidel B, Smith RJ, Chernausek SD, Intrauterine Growth 396 Retardation (IUGR) Study Group. IGF-I receptor mutations resulting in intrauterine and postnatal growth retardation. N Engl J Med 2003;349:2211-22.

3987 Yang L, Xu D, Sun C, Wu J, Wei H, Liu Y, Zhang M, Luo F. IGF1R Variants in Patients With 399 Growth Impairment: Four Novel Variants and Genotype-Phenotype Correlations. J Clin Endocrinol Metab $400 \quad 2018 ; 103: 3939-44$.

4018 Gannage-Yared M-H, Klammt J, Chouery E, Corbani S, Megarbane H, Abou Ghoch J, Choucair 402 N, Pfaffle R, Megarbane A. Homozygous mutation of the IGF1 receptor gene in a patient with severe pre403 and postnatal growth failure and congenital malformations. Eur J Endocrinol 2012;168:K1-7.

4049 Walenkamp MJE, van der Kamp HJ, Pereira AM, Kant SG, van Duyvenvoorde HA, Kruithof MF, Breuning MH, Romijn JA, Karperien M, Wit JM. A variable degree of intrauterine and postnatal growth retardation in a family with a missense mutation in the insulin-like growth factor I receptor. J Clin Endocrinol Metab 2006;91:3062-70.

40810 Fang P, Schwartz ID, Johnson BD, Derr MA, Roberts CT, Hwa V, Rosenfeld RG. Familial Short 409 Stature Caused by Haploinsufficiency of the Insulin-Like Growth Factor I Receptor due to Nonsense410 Mediated Messenger Ribonucleic Acid Decay. J Clin Endocrinol Metab 2009;94:1740-7.

41111 Soellner L, Spengler S, Begemann M, Wollmann HA, Binder G, Eggermann T. IGF1R mutation 412 analysis in short children with Silver-Russell syndrome features. J Pediatr Genet 2013;2:113-7.

41312 Prontera P, Micale L, Verrotti A, Napolioni V, Stangoni G, Merla G. A New Homozygous IGF1R 414 Variant Defines a Clinically Recognizable Incomplete Dominant form of SHORT Syndrome. Hum Mutat $415 \quad 2015 ; 36: 1043-7$.

41613 Wakeling EL, Brioude F, Lokulo-Sodipe O, O'Connell SM, Salem J, Bliek J, Canton APM, 417 Chrzanowska KH, Davies JH, Dias RP, Dubern B, Elbracht M, Giabicani E, Grimberg A, Grønskov K, 418 Hokken-Koelega ACS, Jorge AA, Kagami M, Linglart A, Maghnie M, Mohnike K, Monk D, Moore GE, 419 Murray PG, Ogata T, Petit IO, Russo S, Said E, Toumba M, Tümer Z, Binder G, Eggermann T, Harbison 420 MD, Temple IK, Mackay DJG, Netchine I. Diagnosis and management of Silver-Russell syndrome: first 421 international consensus statement. Nat Rev Endocrinol 2017;13:105-24.

42214 Walenkamp MJE, Robers JML, Wit JM, Zandwijken GRJ, van Duyvenvoorde HA, Oostdijk W, 423 Hokken-Koelega ACS, Kant SG, Losekoot M. Phenotypic features and response to growth hormone 424 treatment of patients with a molecular defect of the IGF-1 receptor. J Clin Endocrinol Metab Published 425 Online First: 8 March 2019. doi:10.1210/jc.2018-02065

42615 Janchevska A, Krstevska-Konstantinova M, Pfäffle H, Schlicke M, Laban N, Tasic V, Gucev Z, 427 Mironska K, Dimovski A, Kratzsch J, Klammt J, Pfäffle R. IGF1R Gene Alterations in Children Born 428 Small for Gestitional Age (SGA). Open Access Maced J Med Sci 2018;6. doi:10.3889/oamjms.2018.416 
430 D, Werner H, de Vries L. A novel heterozygous IGF-1 receptor mutation associated with hypoglycemia.

431 Endocr Connect 2017;6:395-403.

43217 Kruis T, Klammt J, Galli-Tsinopoulou A, Wallborn T, Schlicke M, Müller E, Kratzsch J, Körner

433 A, Odeh R, Kiess W, Pfäffle R. Heterozygous mutation within a kinase-conserved motif of the insulin-like 434 growth factor I receptor causes intrauterine and postnatal growth retardation. J Clin Endocrinol Metab 435 2010;95:1137-42.

43618 Labarta JI, Barrio E, Audí L, Fernández-Cancio M, Andaluz P, de Arriba A, Puga B, Calvo MT, 437 Mayayo E, Carrascosa A, Ferrández-Longás A. Familial short stature and intrauterine growth retardation 438 associated with a novel mutation in the IGF-I receptor ( IGF1R ) gene. Clin Endocrinol (Oxf) $4392013 ; 78: 255-62$.

44019 Ester WA, van Duyvenvoorde HA, de Wit CC, Broekman AJ, Ruivenkamp CAL, Govaerts LCP, 441 Wit JM, Hokken-Koelega ACS, Losekoot M. Two Short Children Born Small for Gestational Age with 442 Insulin-Like Growth Factor 1 Receptor Haploinsufficiency Illustrate the Heterogeneity of Its Phenotype. J 443 Clin Endocrinol Metab 2009;94:4717-27.

44420 Fujimoto M, Kawashima Sonoyama Y, Hamajima N, Hamajima T, Kumura Y, Miyahara N, 445 Nishimura R, Adachi K, Nanba E, Hanaki K, Kanzaki S. Heterozygous nonsense mutations near the C446 terminal region of IGF1R in two patients with small-for-gestational-age-related short stature. Clin 447 Endocrinol (Oxf) 2015;83:834-41.

44821 Usher R, McLean F. Intrauterine growth of live-born Caucasian infants at sea level: standards 449 obtained from measurements in 7 dimensions of infants born between 25 and 44 weeks of gestation. $\mathrm{J}$ 450 Pediatr 1969;74:901-10.

45122 Sempé A, Pedron G, Roy-Pernot M-P. Auxologie, méthode et séquences. Paris: : Laboratoires 452 Théraplix 1979.

45323 Azzi S, Steunou V, Tost J, Rossignol S, Thibaud N, Das Neves C, Le Jule M, Habib WA, Blaise 454 A, Koudou Y, Busato F, Le Bouc Y, Netchine I. Exhaustive methylation analysis revealed uneven profiles 455 of methylation at IGF2/ICR1/H19 11p15 loci in Russell Silver syndrome. J Med Genet 2015;52:53-60.

45624 Richards S, Aziz N, Bale S, Bick D, Das S, Gastier-Foster J, Grody WW, Hegde M, Lyon E, 457 Spector E, Voelkerding K, Rehm HL, ACMG Laboratory Quality Assurance Committee. Standards and 458 guidelines for the interpretation of sequence variants: a joint consensus recommendation of the American 459 College of Medical Genetics and Genomics and the Association for Molecular Pathology. Genet Med Off 460 J Am Coll Med Genet 2015;17:405-24.

46125 Brabant G, von zur Mühlen A, Wüster C, Ranke MB, Kratzsch J, Kiess W, Ketelslegers J-M, 462 Wilhelmsen L, Hulthén L, Saller B, Mattsson A, Wilde J, Schemer R, Kann P. Serum Insulin-Like Growth 463 Factor I Reference Values for an Automated Chemiluminescence Immunoassay System: Results from a 464 Multicenter Study. Horm Res Paediatr 2003;60:53-60. 
26 Azzi S, Salem J, Thibaud N, Chantot-Bastaraud S, Lieber E, Netchine I, Harbison MD. A prospective study validating a clinical scoring system and demonstrating phenotypical-genotypical correlations in Silver-Russell syndrome. J Med Genet 2015;52:446-53.

27 Raile K, Klammt J, Schneider A, Keller A, Laue S, Smith R, Pfäffle R, Kratzsch J, Keller E, Kiess W. Clinical and Functional Characteristics of the Human Arg59Ter Insulin-Like Growth Factor I Receptor ( IGF1R ) Mutation: Implications for a Gene Dosage Effect of the Human IGF1R. J Clin Endocrinol Metab 2006;91:2264-71.

28 Choi J-H, Kang M, Kim G-H, Hong M, Jin HY, Lee B-H, Park J-Y, Lee S-M, Seo E-J, Yoo H-W. Clinical and Functional Characteristics of a Novel Heterozygous Mutation of the IGF1R Gene and IGF1R Haploinsufficiency due to Terminal 15q26.2-\&gt;qter Deletion in Patients with Intrauterine Growth Retardation and Postnatal Catch-Up Growth Failure. J Clin Endocrinol Metab 2011;96:E130-4.

29 Wallborn T, Wüller S, Klammt J, Kruis T, Kratzsch J, Schmidt G, Schlicke M, Müller E, van de Leur HS, Kiess W, Pfäffle R. A heterozygous mutation of the insulin-like growth factor-I receptor causes retention of the nascent protein in the endoplasmic reticulum and results in intrauterine and postnatal growth retardation. J Clin Endocrinol Metab 2010;95:2316-24.

30 Ocaranza P, Golekoh MC, Andrew SF, Guo MH, Kaplowitz P, Saal H, Rosenfeld RG, Dauber A, Cassorla F, Backeljauw PF, Hwa V. Expanding Genetic and Functional Diagnoses of IGF1R Haploinsufficiencies. Horm Res Paediatr Published Online First: 10 April 2017. doi:10.1159/000464143

31 Gat-Yablonski G, De Luca F. Effect of Nutrition on Statural Growth. Horm Res Paediatr 2017;88:46-62.

32 Rudaks LI, Nicholl JK, Bratkovic D, Barnett CP. Short stature due to 15q26 microdeletion involving IGF1R: Report of an additional case and review of the literature. Am J Med Genet A 2011;155:3139-43.

33 Bruce S, Hannula-Jouppi K, Puoskari M, Fransson I, Simola KOJ, Lipsanen-Nyman M, Kere J. Submicroscopic genomic alterations in Silver-Russell syndrome and Silver-Russell-like patients. J Med Genet 2010;47:816-22.

34 Meyer R, Soellner L, Begemann M, Dicks S, Fekete G, Rahner N, Zerres K, Elbracht M, Eggermann T. Targeted Next Generation Sequencing Approach in Patients Referred for Silver-Russell Syndrome Testing Increases the Mutation Detection Rate and Provides Decisive Information for Clinical Management. J Pediatr 2017;187:206-212.e1.

\section{TABLES}

Table 1. Description of the identified single nucleotide variants in the cohort and predictions of the pathological consequences. ACMP/AMP: American College of Medical Genetics and Genomics and the Association for Molecular Pathology classification of variants [24]. PS3 corresponds to a pathogenic 
effect in functional test. AF: allele frequency. \# Classification performed using the InterVar classification 501 system; § First reported in Walenkamp et al. [14]. ๔ Classified as "variant of unknown significance" 502 before the functional test results.

503 Table 2. Clinical features of the patients with IGF1R defects. SNV: Single nucleotide variant. WA: weeks 504 of amenorrhea; SDS: standard deviation score; SGA: born small for gestational age; HC: head 505 circumference; rGH: recombinant growth hormone. \# Items included in the Netchine-Harbison clinical 506 scoring system for Silver-Russell syndrome diagnosis.

\section{FIGURES}

508 Figure 1. A. Schematic representation of the position of $I G F 1 R$ on chromosome 15. B. Representation of 509 the eight identified deletions using the UCSC (University of California Santa Cruz) software. C. 510 Representation of the identified single nucleotide variants (SNV) from exons 1 to 21. Arrows indicate the 511 SNVs identified in the cohort. The corresponding functional domains of the protein are shown to the right. 512 L1 and 2: leucine-rich repeat domains; CR: cysteine-rich region; FN1 to 3: fibronectine type III domains; 513 TM: trans-membrane region; TK: tyrosine kinase domain; CT: C-terminal segment.

514 Figure 2. Growth curves and pedigree of the family of the patient carrying the homozygous variant 515 F112L/F112L. SDS: standard score deviation; NGT: naso-gastric tube.

516 Figure 3. A. Western blot showing phosphorylated-AKT (P-AKT), total AKT, and GAPDH for patients 517 and controls. B. Quantification of AKT phosphorylation calculated as: $R$ after IGF-I stimulation / $R$ not 518 stimulated, with $R=\quad$ [(P-AKTpatient/AKTpatient $) /$ GAPDHpatient $] / \quad[(\mathrm{P}-$ 519 AKTcontrol/AKTcontrol)/GAPDHcontrol]. *p $<0.05$; **p $<0.01$; WT: wild type allele. Experiments 520 were repeated from 3 to 6 times for each individual. Error bars represent the standard error of the mean. 521 Del ex1-21 corresponds to Del4 in figure 1 and Del ex20-21 to Del7.

\section{STATEMENTS}

523 Competing interests: The authors have nothing to disclose. 
525 Eloïse Giabicani: wrote the manuscript, performed the experiments, collected and analyzed the data and 526 revised the manuscript. Marjolaine Willems: collected and analyzed the data and revised the manuscript' 527 Virginie Steunou: performed the experiments. Sandra Chantot-Bastaraud: performed the experiments, 528 analyzed the data and helped in revising the manuscript. Nathalie Thibaud: performed the experiments 529 Walid Abi Habib: analyzed the data and helped in revising the manuscript. Salah Azzi : performed the 530 experiments, analyzed the data and helped in revising the manuscript. Bich Lam: performed the 531 experiments, analyzed the data and helped in revising the manuscript. Laurence Bérard: collected data and 532 helped to revise the manuscript. Hélène Bony-Trifunovic: collected data and helped to revise the 533 manuscript. Cécile Brachet: collected data and helped to revise the manuscript. Elise Brischoux-Boucher: 534 collected data and helped to revise the manuscript. Emmanuelle Caldagues: collected data and helped to 535 revise the manuscript. Régis Coutant: collected data and helped to revise the manuscript. Marie-Laure 536 Cuvelier: collected data and helped to revise the manuscript. Georges Gelwane: collected data and helped 537 to revise the manuscript. Isabelle Guemas: collected data and helped to revise the manuscript. Muriel 538 Houang: collected data and helped to revise the manuscript. Bertrand Isidor: collected data and helped to 539 revise the manuscript. Claire Jeandel: collected data and helped to revise the manuscript. James 540 Lespinasse: collected data and helped to revise the manuscript. Catherine Naud-Saudreau: collected data 541 and helped to revise the manuscript. Monique Jesuran-Perelroizen: collected data and helped to revise the 542 manuscript. Laurence Perrin-Sabourin: collected data and helped to revise the manuscript. Juliette Piard: 543 collected data and helped to revise the manuscript. Claire Sechter: collected data and helped to revise the 544 manuscript. Pierre-François Souchon: collected data and helped to revise the manuscript. Caroline Storey: 545 collected data and helped to revise the manuscript. Domitille Thomas: performed the experiments, 546 collected data and helped to revise the manuscript. Yves Le Bouc: collected data and helped to revise the 547 manuscript. Sylvie Rossignol: collected data and helped to revise the manuscript. Irène Netchine: analyzed 
548 the data and revised the manuscript. Frédéric Brioude: analyzed the data, wrote and revised the 549 manuscript. 
A.

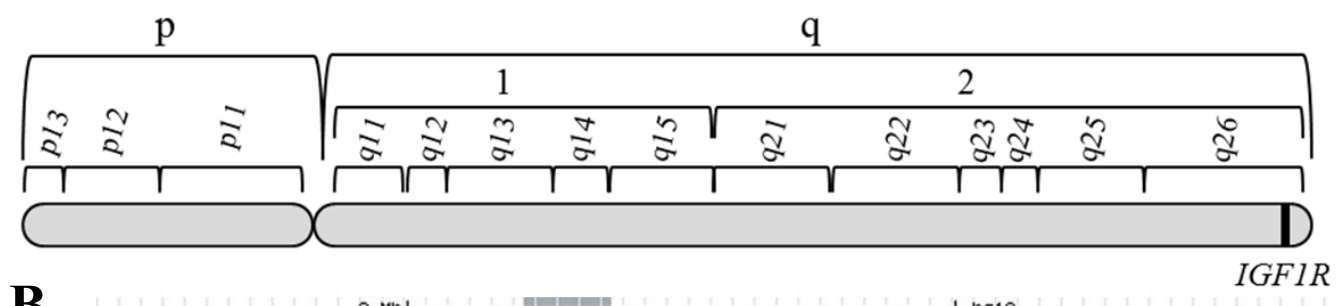

B.
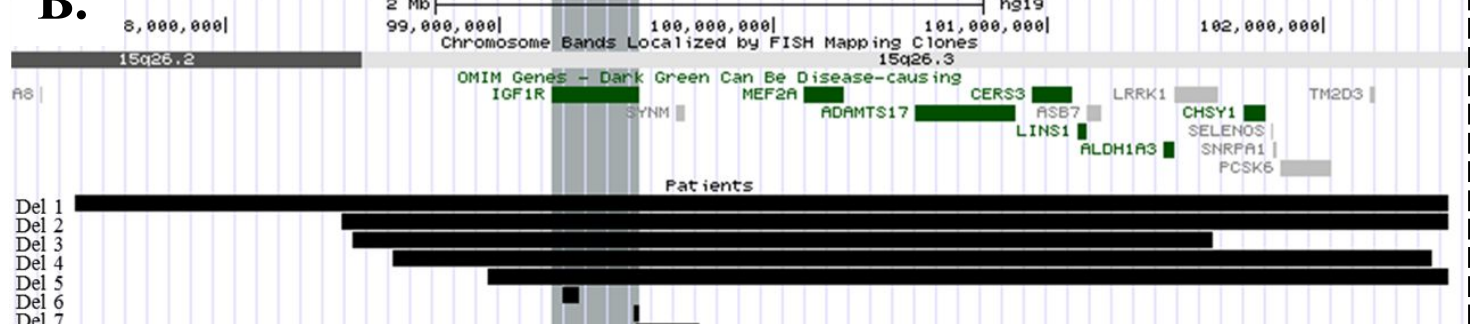

\begin{tabular}{|c|c|c|}
\hline Name & Position [Hg19] & $\operatorname{Size}(\mathbf{K b})$ \\
\hline Dell & chr15 : 97450781-102461162 & 5010.4 \\
\hline Del2 & chr15 : 98426952-102461162 & 4034.2 \\
\hline Del3 & chr15 : 98464591-101599113 & 3134.5 \\
\hline Del4 & chr15 : 98610818-102397836 & 3787.0 \\
\hline Del5 & chr15 : 98954957-102461162 & 3506.2 \\
\hline Del6 & chr15 : 99229330-99290406 & 61.1 \\
\hline Del7 & chr15 : 99492046-99511073 & 19.0 \\
\hline Del8 & chr15 : 99496341-99730813 & 234.5 \\
\hline
\end{tabular}

C.

IGF1R

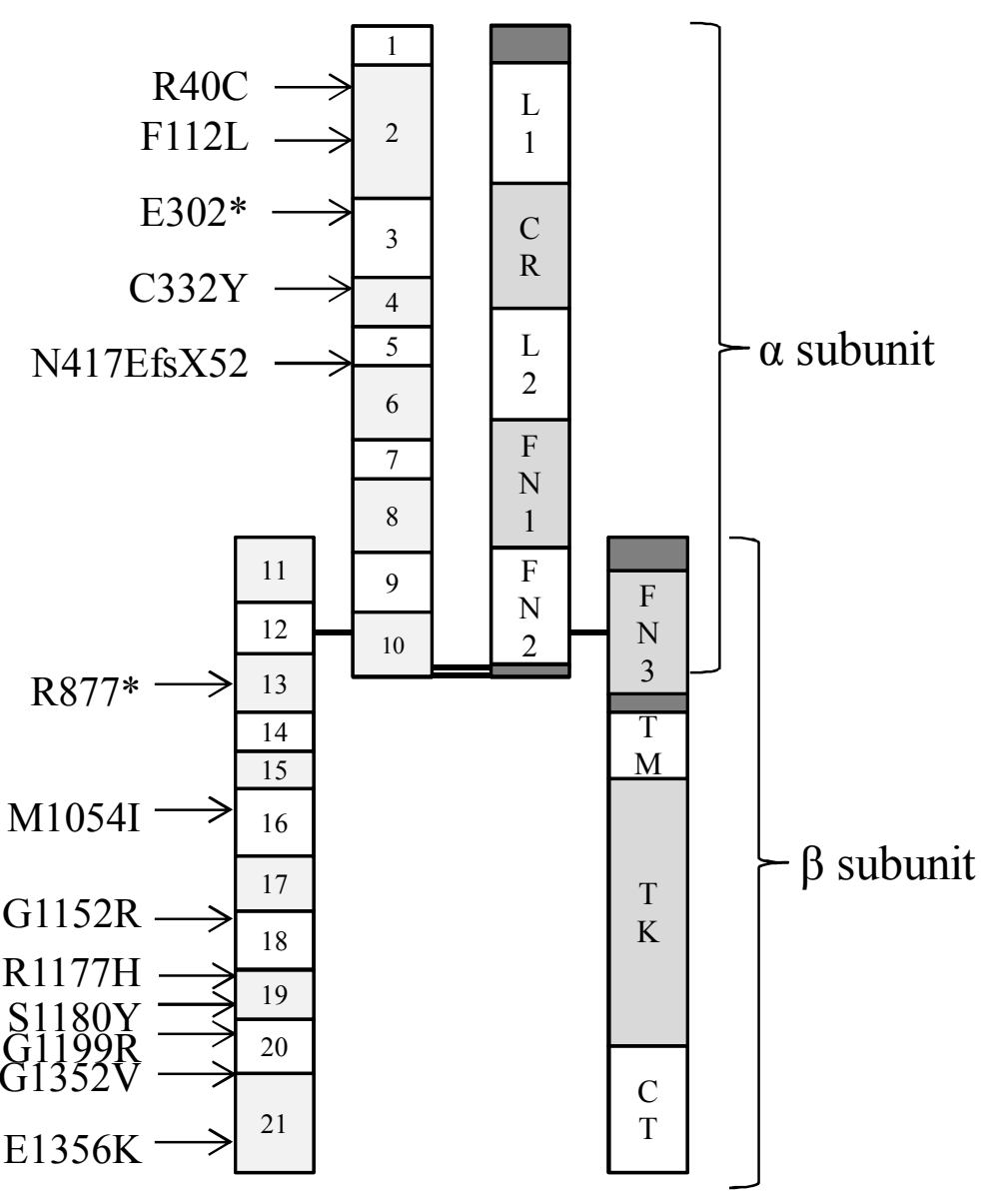



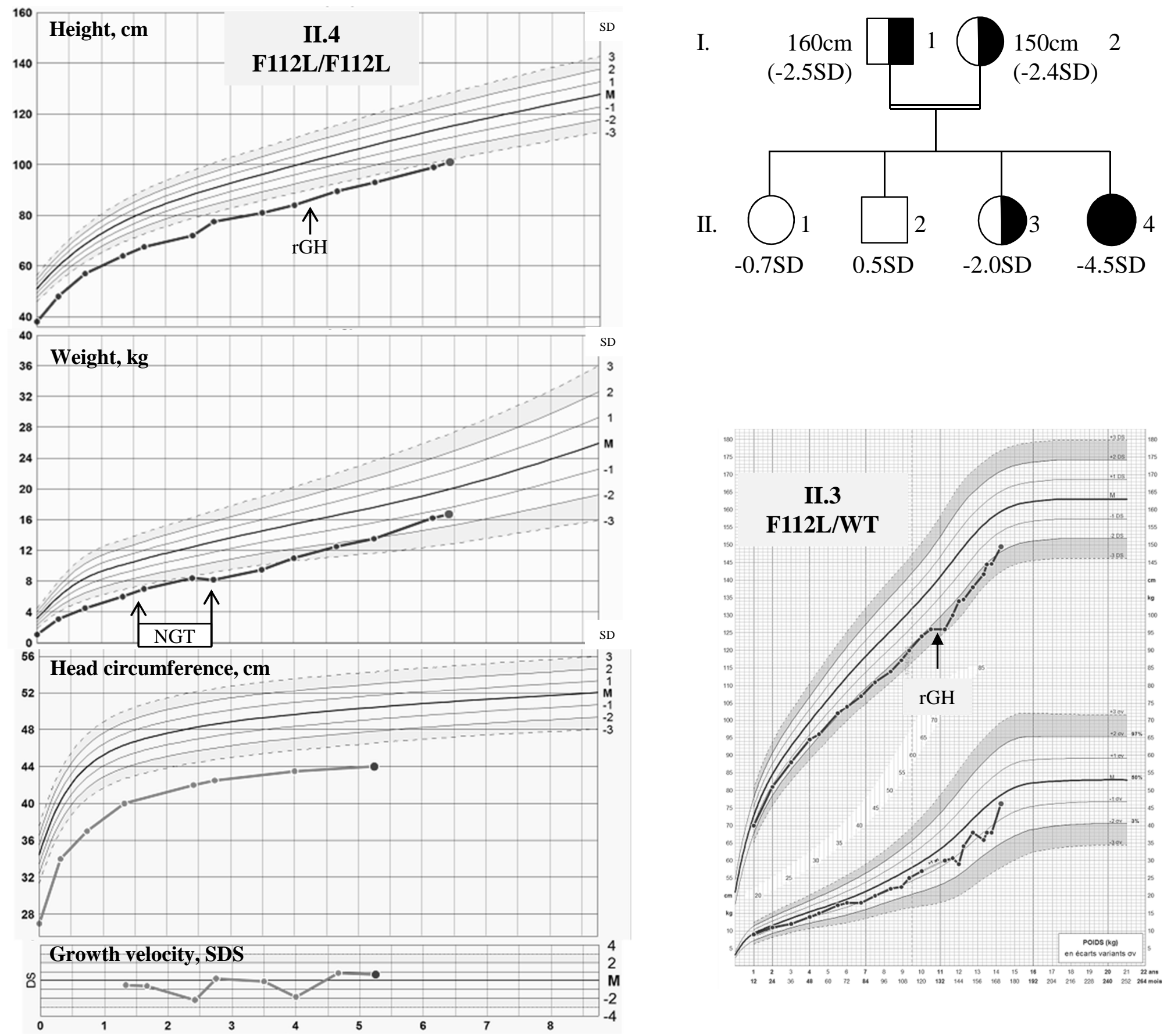


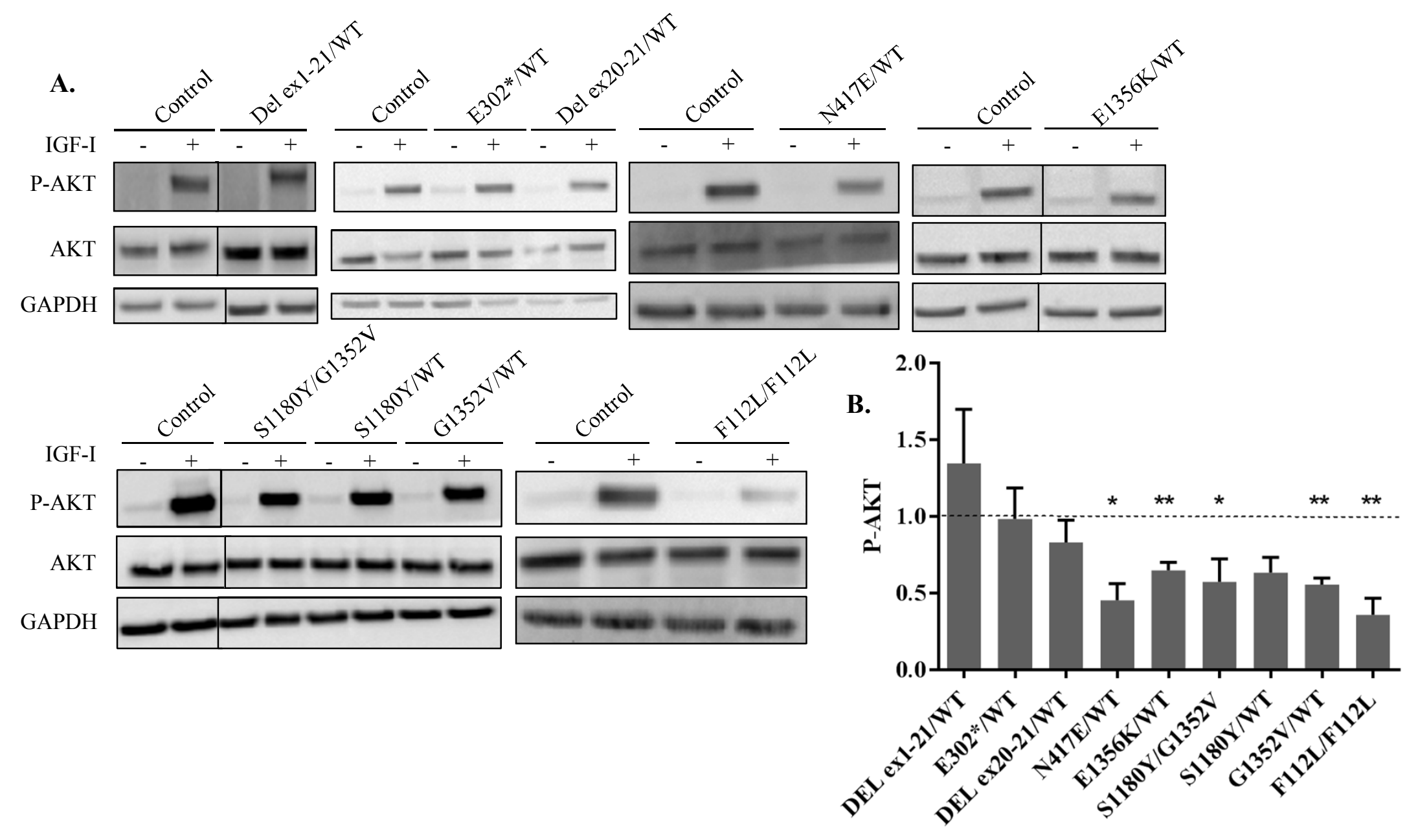




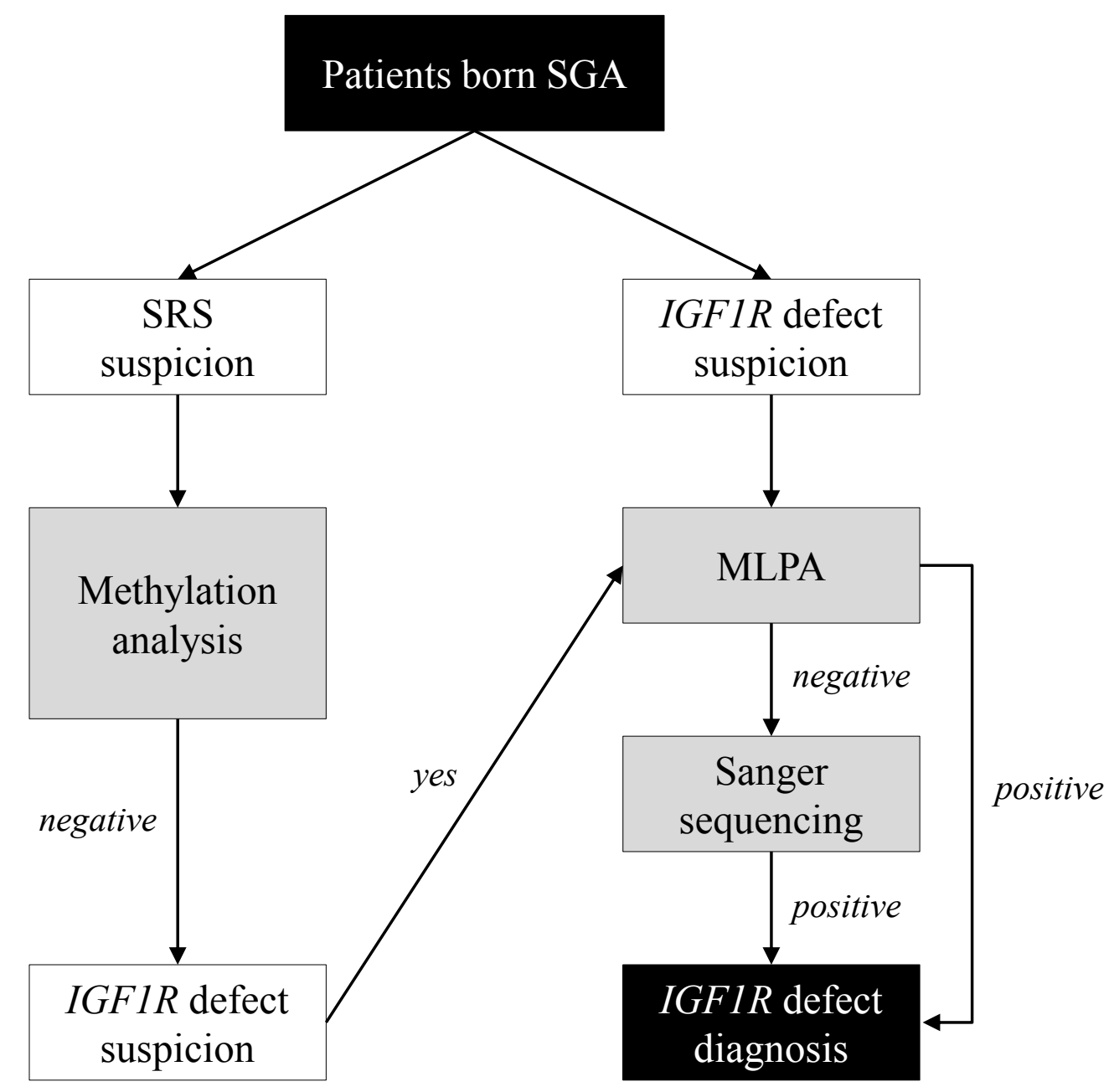




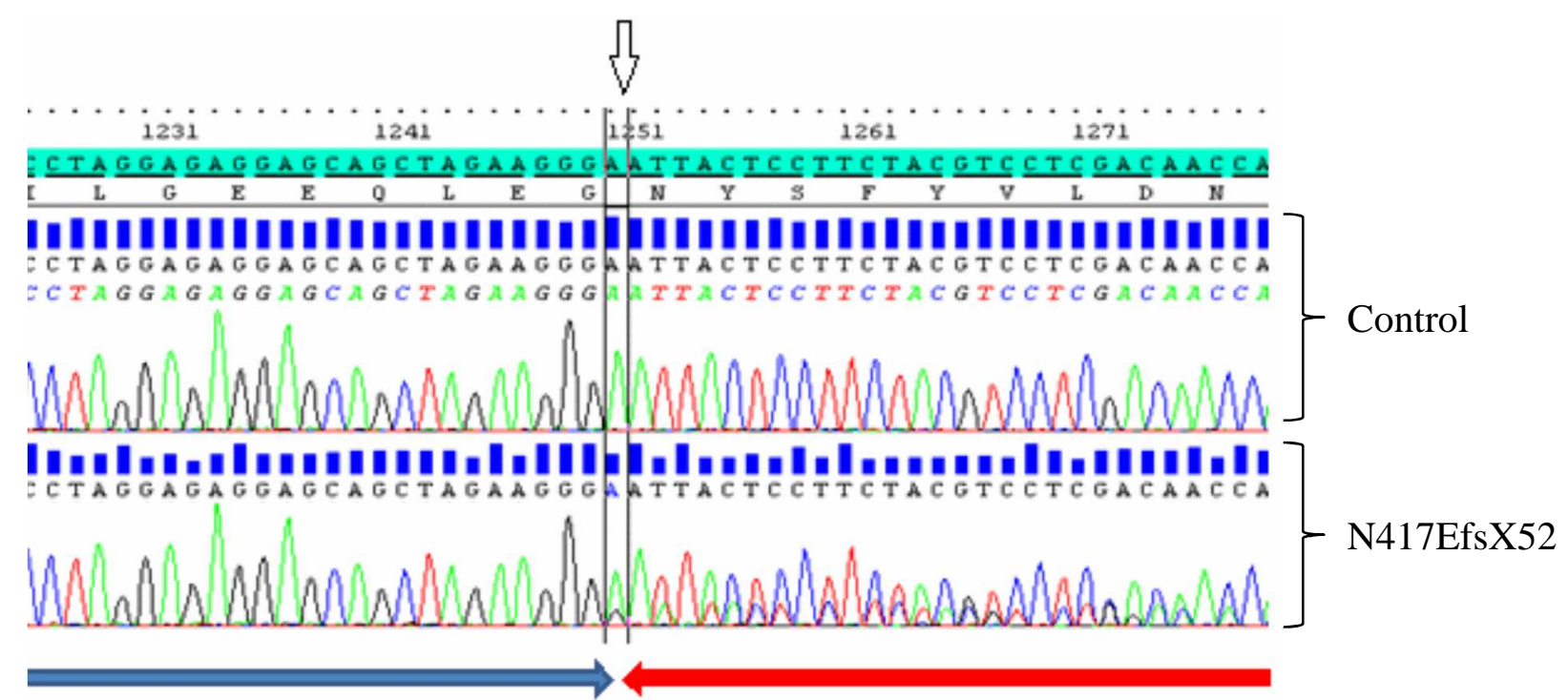

Exon 5

Exon 6 


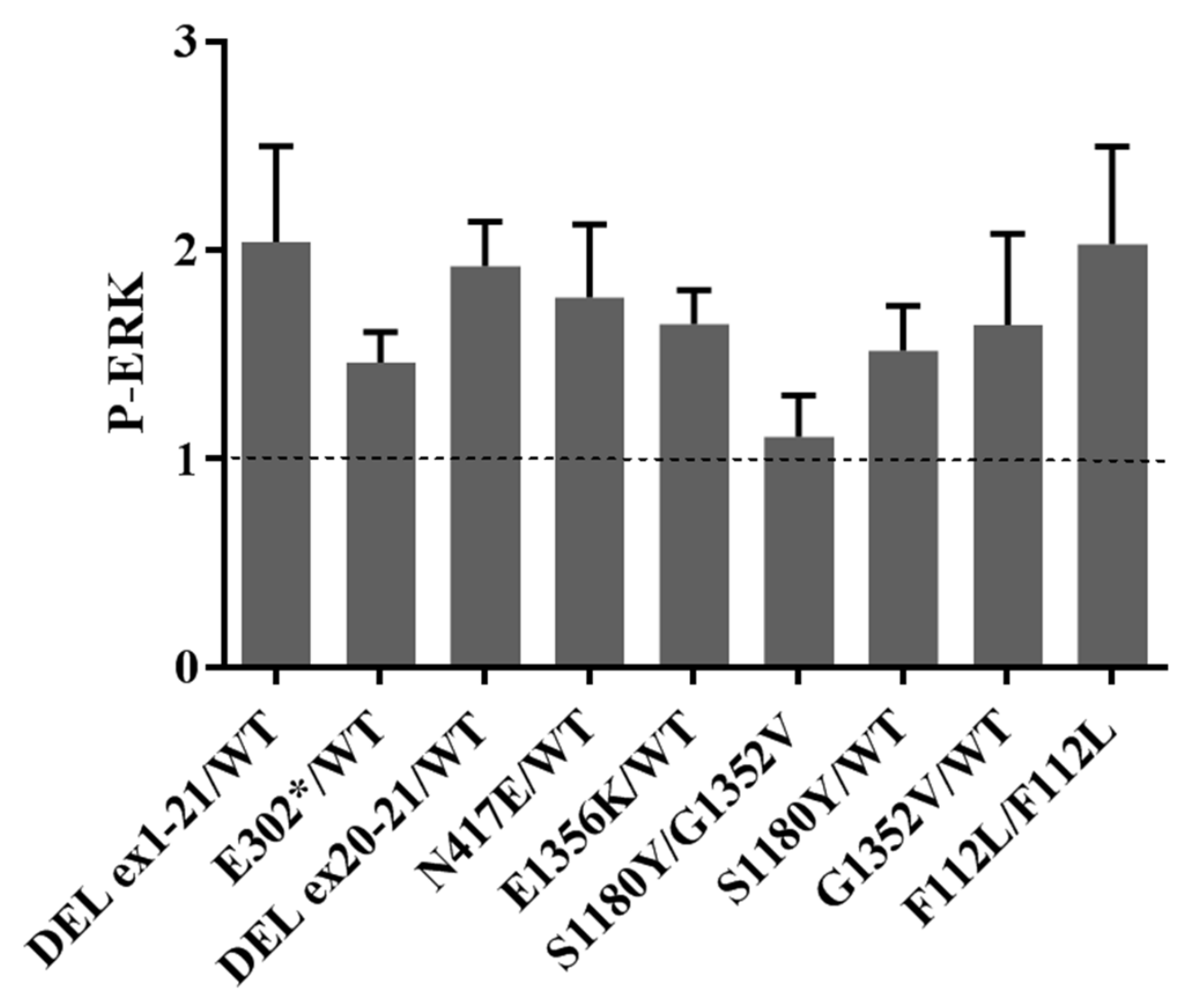




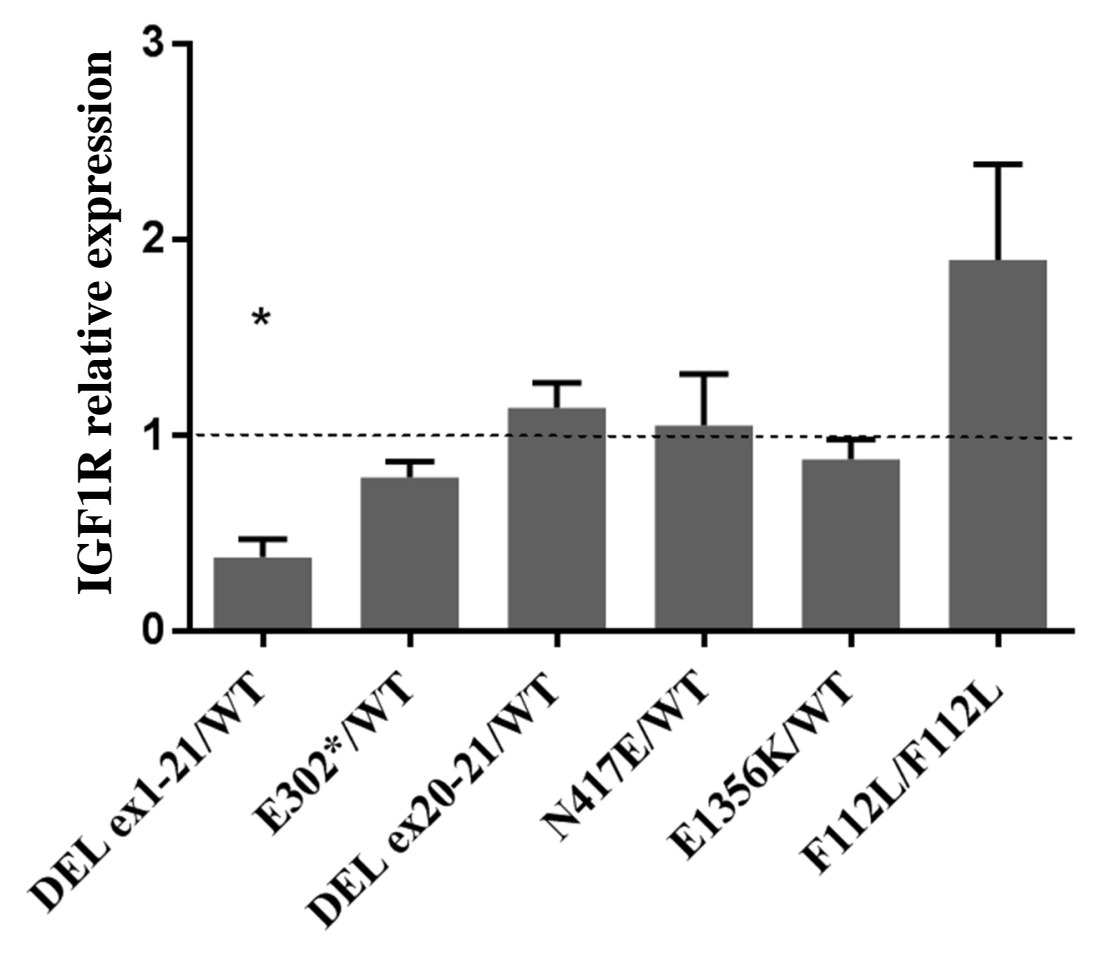




\section{ABBREVIATIONS}

ADHD: attention deficit hyperactivity disorder

$B L$ : birth length

BW: birth weight

DVT: developmental

GnRH: gonadotropin

HC: head circumference

HTZ cp: compound HTZ

HTZ: heterozygous

IAC: interatrial communication

min: minimum

NA: not available

POF: patent foramen ovale

rGH: recombinant

growth hormone

SDS: standard deviation score

SRS: Silver-Russell syndrome

WA: weeks of amenorrhea

\begin{tabular}{|c|c|c|c|c|c|c|c|c|c|}
\hline \multicolumn{2}{|c|}{ PATIENTS } & \multicolumn{4}{|c|}{ GENETICS } & \multicolumn{3}{|c|}{ FAMILY } & \multirow[b]{2}{*}{$\begin{array}{r}\text { TERM } \\
\text { (WA) }\end{array}$} \\
\hline NAME & SEX & NOMENCLATURE & PROTEIN & $\begin{array}{l}\text { ALLELIC } \\
\text { STATUS }\end{array}$ & SEGREGATION & $\begin{array}{c}\text { MOTHER } \\
\text { HEIGHT (SDS) }\end{array}$ & $\begin{array}{c}\text { FATHER } \\
\text { HEIGHT (SDS) }\end{array}$ & $\begin{array}{c}\text { TARGET } \\
\text { HEIGHT (SDS) }\end{array}$ & \\
\hline patient1 & M & 15q26.3(98954957_102461162)x1 & NA & HTZ & mother & $-4,1$ & $-0,5$ & $-2,1$ & 40 \\
\hline relative1 & $\mathrm{F}$ & 15q26.3(98954957_102461162)x1 & NA & HTZ & unknown & $-0,6$ & $-1,7$ & $-1,3$ & NA \\
\hline patient2 & M & 15q26.3(98610818_102397836)x1 & NA & HTZ & de novo & 1,9 & 0,8 & 1,4 & 39 \\
\hline patient3 & M & 15q26.2q26.3(98426952_102461162)x 1 & NA & HTZ & unknown & $-2,4$ & 1,4 & $-0,3$ & 37 \\
\hline patient4 & M & 15q26.2q26.3(97450781_102461162)×1 & NA & HTZ & unknown & 0 & 2,4 & 1,3 & 39 \\
\hline patient5 & $\mathrm{F}$ & 15q26.2q26.3(98464591_101599113)x1 & NA & HTZ & de novo & $-1,6$ & 0,8 & $-0,5$ & 37 \\
\hline patient6 & M & 15q26.3(99492046_99511073)x1 & NA & HTZ & unknown & NA & NA & NA & NA \\
\hline relative6 & M & 15q26.3(99492046_99511073)x1 & NA & HTZ & father & $-1,6$ & $-3,5$ & $-2,8$ & 38,3 \\
\hline patient7 & $\mathrm{F}$ & 15q26.3(99496341_99730813)x1 & NA & HTZ & de novo & $-1,5$ & $-1,7$ & $-1,7$ & 35 \\
\hline patient8 & $\mathrm{F}$ & 15q26.3(99229330_99290406)x1 & NA & HTZ & father & $-1,5$ & $-1,2$ & $-1,5$ & 32 \\
\hline relative8a & M & 15q26.3(99229330_99290406)x1 & NA & HTZ & father & $-1,5$ & $-1,2$ & $-1,2$ & 31 \\
\hline relative8b & $M$ & 15q26.3(99229330_99290406)x1 & NA & HTZ & unknown & $-3,8$ & 0 & $-1,7$ & 41 \\
\hline patient9 & M & c. $118 \mathrm{C}>\mathrm{T}$ & $\mathrm{R} 40 \mathrm{C}$ & $\mathrm{HTZ}$ & unknown & $-0,9$ & $-3,3$ & -2 & 41 \\
\hline patient10 & $\mathrm{F}$ & c. $384 \mathrm{~T}>\mathrm{C}$ & $\mathrm{F} 112 \mathrm{~L}$ & $\mathrm{HMZ}$ & father + mother & $-2,4$ & $-2,5$ & $-2,6$ & 34 \\
\hline relative10a & $\mathrm{F}$ & c.384T $>C$ & F112L & $\mathrm{HTZ}$ & unknown & 0,3 & -1 & $-0,5$ & NA \\
\hline relative10b & $\mathrm{F}$ & c. $384 \mathrm{~T}>\mathrm{C}$ & F112L & HTZ & unknown & $-2,4$ & $-2,5$ & $-2,6$ & NA \\
\hline relative10c & $M$ & c. $384 \mathrm{~T}>\mathrm{C}$ & $\mathrm{F} 112 \mathrm{~L}$ & HTZ & unknown & $-2,4$ & 0 & -1 & NA \\
\hline patient11 & $\mathrm{F}$ & c.904G>T & $\mathrm{E} 302 *$ & HTZ & unknown & $-2,2$ & $-2,5$ & $-2,5$ & 34 \\
\hline patient12 & $\mathrm{F}$ & c. $995 \mathrm{G}>\mathrm{A}$ & $\mathrm{C} 332 \mathrm{Y}$ & HTZ & father & $-1,8$ & $-1,3$ & $-1,7$ & 40 \\
\hline relative12 & M & c. $995 \mathrm{G}>\mathrm{A}$ & $\mathrm{C} 332 \mathrm{Y}$ & HTZ & unknown & NA & NA & NA & NA \\
\hline patient13 & $M$ & c. $1247+1-1247+2$ insG & N417EfsX52 & HTZ & mother & $-2,8$ & $-0,5$ & $-1,4$ & 41,5 \\
\hline relative13 & $\mathrm{F}$ & c. $1247+1-1247+2$ insG & N417EfsX52 & HTZ & unknown & $-2,9$ & -2 & $-2,2$ & NA \\
\hline patient14 & M & c. $2629 C>T$ & R877* & HTZ & unknown & $-1,3$ & -1 & -1 & 37 \\
\hline patient15 & $M$ & c. $3162 \mathrm{G}>\mathrm{A}$ & M1054I & HTZ & unknown & $-0,6$ & $-0,8$ & $-0,6$ & 38,5 \\
\hline patient16 & $\mathrm{F}$ & c. $3454 \mathrm{G}>\mathrm{A}$ & G1152R & HTZ & father & $-2,9$ & $-4,1$ & $-3,8$ & 40 \\
\hline relative16a & $M$ & c. $3454 \mathrm{G}>\mathrm{A}$ & G1152R & HTZ & unknown & $-2,4$ & $-1,7$ & $-1,8$ & NA \\
\hline relative $16 \mathrm{~b}$ & M & c. $3454 \mathrm{G}>\mathrm{A}$ & G1152R & HTZ & father & $-2,9$ & $-4,1$ & $-3,3$ & 39 \\
\hline patient17 & $M$ & c. $3530 \mathrm{G}>\mathrm{A}$ & R1177H & $\mathrm{HTZ}$ & unknown & $-3,2$ & $-2,2$ & $-2,5$ & 38 \\
\hline patient18 & M & c. $3539 \mathrm{C}>\mathrm{A} / \mathrm{c} .4055 \mathrm{G}>\mathrm{T}$ & S1180Y/G1352V & HTZ comp & father + mother & $-2,4$ & 1 & $-0,7$ & 40 \\
\hline relative18a & M & c. $4055 \mathrm{G}>\mathrm{T}$ & G1352V & HTZ & unknown & NA & NA & NA & NA \\
\hline relative $18 \mathrm{~b}$ & $\mathrm{~F}$ & c. $3539 C>A$ & S1180Y & HTZ & unknown & NA & NA & NA & NA \\
\hline patient19 & $\mathrm{F}$ & c. $3595 \mathrm{G}>\mathrm{A}$ & G1199R & HTZ & mother & $-2,9$ & 0 & $-1,6$ & 38,5 \\
\hline relative19 & $\mathrm{F}$ & c. $3595 \mathrm{G}>\mathrm{A}$ & G1199R & HTZ & unknown & NA & NA & NA & NA \\
\hline patient20 & $\mathrm{F}$ & c. $4066 \mathrm{G}>\mathrm{A}$ & E1356K & HTZ & father & $-1,1$ & 0,5 & $-0,4$ & 37 \\
\hline relative20 & $M$ & c. $4066 \mathrm{G}>\mathrm{A}$ & E1356K & HTZ & unknown & NA & NA & NA & NA \\
\hline
\end{tabular}




\begin{tabular}{|c|c|c|c|c|c|c|c|c|c|c|c|c|c|c|c|c|}
\hline \multicolumn{3}{|c|}{ BIRTH PARAMETERS } & \multicolumn{5}{|c|}{ rGH THERAPY } & \multicolumn{2}{|c|}{ GROWTH } & \multicolumn{6}{|c|}{ DEVELOPMENT } & \multirow[b]{2}{*}{$\begin{array}{c}\text { FEEDING } \\
\text { DIFFICULTIES }\end{array}$} \\
\hline $\begin{array}{l}\text { WEIGHT } \\
\text { (SDS) }\end{array}$ & $\begin{array}{l}\text { LENGTH } \\
\text { (SDS) }\end{array}$ & $\begin{array}{c}\mathrm{HC} \\
\text { (SDS) }\end{array}$ & $\mathrm{rGH}$ & $\begin{array}{l}\text { AGE AT } \\
\text { ONSET }\end{array}$ & $\begin{array}{l}\text { HEIGHT AT } \\
\text { ONSET (SDS) }\end{array}$ & DURATION & $\begin{array}{c}\text { HEIGHT } \\
\text { GAIN (SDS) }\end{array}$ & $\begin{array}{l}\text { HEIGHT } \\
\min (S D S)\end{array}$ & $\begin{array}{c}\text { FINAL } \\
\text { HEIGHT (SDS) }\end{array}$ & $\begin{array}{l}\text { ASSISTED } \\
\text { SCHOOL }\end{array}$ & $\begin{array}{l}\text { DVT } \\
\text { DELAY }\end{array}$ & $\begin{array}{c}\text { LANGUAGE } \\
\text { DELAY }\end{array}$ & $\begin{array}{c}\text { MOTOR } \\
\text { DELAY }\end{array}$ & $\begin{array}{c}\text { COGNITIVE } \\
\text { DELAY }\end{array}$ & $\begin{array}{c}\mathrm{HC} \\
<-2 \mathrm{SDS}\end{array}$ & \\
\hline$-1,9$ & -2 & -3 & yes & 4,1 & $-3,0$ & 10,9 & 1,4 & $-3,3$ & $-2,4$ & 1 & 1 & 1 & 0 & 1 & 1 & 1 \\
\hline NA & NA & NA & no & - & - & - & - & NA & $-4,1$ & NA & NA & NA & NA & NA & NA & NA \\
\hline$-1,4$ & $-2,3$ & $-1,6$ & no & - & - & - & - & $-2,1$ & $-2,2$ & 1 & 1 & 1 & 0 & 1 & NA & 0 \\
\hline$-2,3$ & $-4,2$ & $-2,33$ & yes & 2,9 & $-5,6$ & on going & on going & $-5,7$ & NA & 1 & 1 & 1 & 1 & 1 & 1 & 1 \\
\hline$-3,2$ & $-3,1$ & -3 & yes & 1,5 & $-4,6$ & 14,7 & 2,5 & $-4,6$ & $-2,1$ & 0 & 0 & 0 & 0 & 0 & 1 & 1 \\
\hline$-2,6$ & $-3,4$ & $-2,3$ & yes & 3,0 & $-5,1$ & 3,5 & 1,5 & $-5,3$ & $-3,8$ & 1 & 1 & 0 & 0 & 1 & 1 & 1 \\
\hline NA & NA & NA & no & - & - & - & - & NA & NA & NA & NA & NA & NA & NA & NA & NA \\
\hline$-2,1$ & $-3,1$ & NA & yes & 6,4 & $-3,1$ & on going & on going & $-3,2$ & $-3,5$ & 1 & 1 & 0 & 0 & 1 & 1 & 1 \\
\hline$-2,5$ & $-3,8$ & $-2,8$ & no & - & - & - & - & $-4,8$ & NA & 0 & 0 & 0 & 0 & 1 & 1 & 0 \\
\hline$-3,5$ & $-3,8$ & $-2,6$ & yes & 2,9 & $-3,5$ & 11,2 & 2,1 & -3 & $-1,8$ & 1 & 1 & 1 & 1 & 1 & 1 & 1 \\
\hline-2 & $-2,5$ & NA & yes & 7,2 & $-1,6$ & 7,2 & 0,7 & $-2,4$ & -1 & 0 & 1 & 0 & 1 & 0 & 0 & 0 \\
\hline$-1,4$ & NA & NA & no & - & - & - & - & NA & $-1,2$ & 0 & 0 & 0 & 0 & 0 & 0 & NA \\
\hline$-2,3$ & $-2,5$ & NA & no & - & - & - & - & $-2,7$ & $-2,7$ & 1 & 0 & 0 & 0 & 0 & 1 & 0 \\
\hline$-3,8$ & -4 & $-3,3$ & yes & 4,1 & $-4,6$ & on going & on going & $-4,5$ & NA & 1 & 1 & 1 & 1 & 1 & 1 & 1 \\
\hline NA & NA & NA & no & - & - & - & - & NA & $-2,4$ & NA & NA & NA & NA & NA & 0 & NA \\
\hline NA & NA & NA & yes & 11,3 & $-2,8$ & on going & on going & $-2,2$ & NA & 1 & NA & NA & NA & NA & 0 & NA \\
\hline NA & NA & NA & no & - & - & - & - & NA & $-2,5$ & NA & NA & NA & NA & NA & 0 & NA \\
\hline-1 & $-1,4$ & $-0,3$ & yes & 12,8 & $-4,4$ & 2,8 & 0,4 & $-4,4$ & $-4,2$ & 1 & 1 & 0 & 0 & 1 & 1 & 0 \\
\hline$-3,2$ & $-4,8$ & $-3,9$ & yes & 9,5 & $-2,7$ & on going & on going & $-2,8$ & NA & 1 & 1 & 0 & 1 & 1 & 1 & 1 \\
\hline NA & NA & NA & no & - & - & - & - & NA & $-1,3$ & NA & NA & NA & NA & NA & NA & NA \\
\hline$-2,8$ & $-3,9$ & NA & yes & 10,4 & $-3,3$ & 5,8 & 0,1 & $-3,3$ & $-3,2$ & 0 & 0 & 0 & 0 & 0 & 1 & 0 \\
\hline NA & NA & NA & no & - & - & - & - & NA & $-2,8$ & NA & NA & NA & NA & NA & NA & NA \\
\hline$-1,8$ & $-3,1$ & $-2,8$ & no & - & - & - & - & -3 & NA & NA & 0 & 0 & 0 & 0 & 1 & 0 \\
\hline$-2,5$ & $-2,9$ & $-0,3$ & yes & 15,3 & $-2,7$ & 0,3 & 0,2 & $-2,6$ & $-2,5$ & 1 & 0 & 0 & 0 & 0 & 1 & 0 \\
\hline$-2,7$ & $-3,3$ & NA & yes & 4,2 & $-4,8$ & 4,3 & 0,1 & $-4,7$ & NA & 1 & 1 & 0 & 0 & 1 & 1 & 1 \\
\hline NA & NA & NA & no & - & - & - & - & NA & $-4,2$ & 0 & NA & NA & NA & NA & NA & NA \\
\hline$-3,7$ & $-5,2$ & $-3,5$ & yes & 11,8 & $-4,5$ & 6,2 & 0,4 & $-4,6$ & $-4,1$ & 0 & 0 & 0 & 0 & 0 & 1 & 1 \\
\hline$-2,6$ & $-4,2$ & $-2,9$ & yes & 5,5 & $-3,4$ & 10,1 & 1,7 & $-3,4$ & -3 & 0 & 0 & 0 & 0 & 0 & 1 & 0 \\
\hline$-2,2$ & $-2,7$ & -3 & no & - & - & - & - & $-2,5$ & NA & 1 & 1 & 1 & 1 & 1 & 1 & 1 \\
\hline NA & NA & NA & no & - & - & - & - & NA & 1 & NA & NA & NA & NA & NA & 0 & NA \\
\hline NA & NA & NA & yes & 7,5 & NA & & NA & NA & $-2,1$ & NA & NA & NA & NA & NA & 1 & NA \\
\hline$-2,1$ & $-3,7$ & $-3,7$ & yes & 11,7 & $-4,3$ & 4,1 & 1,4 & $-4,4$ & $-2,9$ & 0 & 0 & 0 & 0 & 0 & 1 & 0 \\
\hline NA & NA & NA & no & - & - & - & - & NA & $-2,9$ & NA & NA & NA & NA & NA & NA & NA \\
\hline$-2,8$ & $-2,6$ & $-3,6$ & no & - & - & - & - & NA & NA & NA & NA & NA & NA & NA & 0 & 1 \\
\hline NA & NA & NA & no & - & - & - & - & NA & 0,5 & NA & NA & NA & NA & NA & NA & NA \\
\hline
\end{tabular}




\begin{tabular}{|c|c|c|c|c|c|c|c|c|c|c|c|c|c|c|c|c|}
\hline \multirow{2}{*}{$\begin{array}{l}\text { CLINICS } \\
\text { OTHERS }\end{array}$} & \multicolumn{3}{|c|}{ LAST EVALUATION } & \multicolumn{4}{|c|}{ IGF-I BEFORE TREATMENT } & \multicolumn{4}{|c|}{ IGF-I DURING TREATMENT } & \multicolumn{5}{|c|}{ CLINICAL SCORE (Walenkamp et al. 2019) } \\
\hline & AGE & $\begin{array}{c}\text { HEIGHT } \\
\text { (SDS) }\end{array}$ & $\begin{array}{c}\mathrm{HC} \\
\text { (SDS) }\end{array}$ & AGE & $\begin{array}{c}\text { IGF1 } \\
\text { (ng/mL) }\end{array}$ & $\begin{array}{l}\text { IGF-I } \\
\text { SDS }\end{array}$ & $\begin{array}{c}\text { IGF1 } \\
>0 \text { SDS }\end{array}$ & AGE & $\begin{array}{l}\text { IGF1 } \\
\text { (ng/mL) }\end{array}$ & $\begin{array}{l}\text { IGF-I } \\
\text { SDS }\end{array}$ & $\begin{array}{c}\text { IGF1 } \\
>0 \text { SDS }\end{array}$ & SCORE & $\begin{array}{l}\text { BW/BL } \\
<-1 \text { SDS }\end{array}$ & $\begin{array}{c}\text { HEIGHT } \\
<-2,5 \text { SDS }\end{array}$ & $\begin{array}{l}\mathrm{HC} \\
<-2 \text { SDS }\end{array}$ & $\begin{array}{l}\text { IGF1 } \\
>0 \text { SDS }\end{array}$ \\
\hline \multirow[t]{2}{*}{ Hypoglycaemia } & 15,8 & $-1,6$ & $-1,5$ & 3,7 & 279 & 5,5 & 1 & 5,1 & 521 & 8,8 & 1 & 4 & 1 & 1 & 1 & 1 \\
\hline & NA & NA & NA & NA & NA & NA & NA & NA & NA & NA & NA & NA & NA & 1 & NA & NA \\
\hline Knees luxation & 18,9 & $-2,2$ & NA & 8,2 & 460 & 3,6 & 1 & 12,1 & 704 & 2,9 & 1 & $2 / 3$ & 1 & 0 & NA & 1 \\
\hline IAC & 12,8 & $-2,5$ & $-2,8$ & 2,9 & 95 & 0,6 & 1 & 4,2 & 135 & 1,1 & 1 & 4 & 1 & 1 & 1 & 1 \\
\hline Overweight & 18,0 & $-2,1$ & NA & 1,5 & 25 & $-2,0$ & 0 & 2,5 & 169 & 2,9 & 1 & 4 & 1 & 1 & 1 & 1 \\
\hline \multirow[t]{2}{*}{ GnRH analogs } & 15,5 & $-3,6$ & NA & 2,6 & 138 & 1,1 & 1 & 4,2 & 306 & 3,7 & 1 & 4 & 1 & 1 & 1 & 1 \\
\hline & NA & $-3,5$ & NA & 56,2 & 224 & 1,5 & 1 & NA & NA & NA & NA & NA & NA & NA & NA & 1 \\
\hline ADHD & 13,5 & $-3,1$ & NA & NA & NA & NA & NA & 6,7 & 460 & 6,0 & 1 & 4 & 1 & 1 & 1 & 1 \\
\hline \multirow[t]{2}{*}{ IAC } & 10,4 & $-4,5$ & $-5,1$ & 10,3 & 414 & 0,6 & 1 & NA & NA & NA & & 4 & 1 & 1 & 1 & 1 \\
\hline & 14,0 & $-1,4$ & NA & 1,9 & 112 & 0,9 & 1 & 5,9 & 220 & 1,3 & 1 & 4 & 1 & 1 & 1 & 1 \\
\hline \multirow[t]{3}{*}{ ADHD, cryptorchidism } & 19,1 & $-0,9$ & NA & 7,2 & 142 & $-0,3$ & 0 & 9,2 & 556 & 3,9 & 1 & 2 & 1 & 0 & 0 & 1 \\
\hline & 49,5 & $-1,2$ & $-1,6$ & NA & NA & NA & NA & NA & NA & NA & NA & NA & 1 & NA & 0 & NA \\
\hline & 17,0 & $-2,5$ & na & 14,7 & 968 & 4,5 & 1 & NA & NA & NA & NA & 3 & 1 & 0 & 1 & 1 \\
\hline \multirow[t]{2}{*}{ POF, hypothyroidism } & 5,2 & $-3,7$ & $-4,9$ & 4,0 & 314 & 4,3 & 1 & 5,2 & 710 & 9,8 & 1 & 4 & 1 & 1 & 1 & 1 \\
\hline & NA & NA & NA & NA & NA & NA & NA & NA & NA & NA & NA & NA & NA & NA & 0 & NA \\
\hline \multirow[t]{2}{*}{ ADHD } & 13,7 & $-2,2$ & NA & 11,3 & 269,3 & $-1,2$ & 0 & 11,7 & 582 & 1,6 & 1 & $1 / 3$ & NA & 0 & 0 & 1 \\
\hline & NA & NA & NA & NA & NA & NA & NA & NA & NA & NA & NA & NA & NA & 1 & 0 & NA \\
\hline GnRH analogs & 15,3 & -4 & NA & 12,8 & 947 & 4,1 & 1 & 13,8 & 1470 & 7,9 & 1 & 4 & 1 & 1 & 1 & 1 \\
\hline \multirow[t]{5}{*}{ ADHD, GnRH analogs } & 11,3 & $-2,2$ & NA & 9,3 & 353 & 0,5 & 1 & 10,3 & 510 & 1,4 & 1 & 4 & 1 & 1 & 1 & 1 \\
\hline & NA & $-1,3$ & NA & NA & NA & NA & NA & NA & NA & NA & NA & NA & NA & NA & NA & NA \\
\hline & 16,6 & $-3,2$ & NA & 10,0 & 252 & $-0,2$ & 0 & 11,6 & 449 & 1,3 & 1 & 4 & 1 & 1 & 1 & 1 \\
\hline & NA & NA & NA & NA & NA & NA & NA & NA & NA & NA & NA & NA & NA & 1 & NA & NA \\
\hline & 7,1 & $-2,2$ & NA & 5,4 & 273 & 3,5 & 1 & NA & NA & NA & NA & 4 & 1 & 1 & 1 & 1 \\
\hline \multirow[t]{2}{*}{ Obesity } & 21,5 & $-2,5$ & $-2,7$ & 15,2 & 1260 & 7,1 & 1 & 16,1 & 908 & 4,4 & 1 & 3 & 1 & 0 & 1 & 1 \\
\hline & 12,6 & $-4,7$ & na & 4,2 & 226 & 2,1 & 1 & 8,1 & 964 & 7,4 & 1 & 4 & 1 & 1 & 1 & 1 \\
\hline \multirow[t]{3}{*}{ Type II diabetes } & NA & NA & NA & NA & NA & NA & NA & NA & NA & NA & NA & NA & NA & 1 & NA & NA \\
\hline & 18,1 & $-4,1$ & $-4,1$ & 11,8 & 300 & $-0,1$ & 0 & 15,7 & 412 & 0,2 & 1 & 4 & 1 & 1 & 1 & 1 \\
\hline & 15,1 & $-1,7$ & NA & 5,6 & 310 & 4,3 & 1 & 6,6 & 653 & 9,5 & 1 & 4 & 1 & 1 & 1 & 1 \\
\hline \multirow[t]{5}{*}{ Pyelic dilatation } & 6,6 & $-1,6$ & $-4,3$ & 5,4 & 304 & 4,2 & 1 & NA & NA & NA & NA & 3 & 1 & 0 & 1 & 1 \\
\hline & NA & NA & NA & NA & NA & NA & NA & NA & NA & NA & NA & NA & NA & NA & 0 & NA \\
\hline & NA & NA & NA & NA & NA & NA & NA & NA & NA & NA & NA & NA & NA & NA & 1 & NA \\
\hline & 20,8 & $-2,9$ & NA & 12,9 & 383 & $-0,2$ & 0 & 14,6 & 790 & 3,0 & 1 & 4 & 1 & 1 & 1 & 1 \\
\hline & NA & NA & NA & NA & NA & NA & NA & NA & NA & NA & NA & NA & NA & 1 & NA & NA \\
\hline \multirow[t]{2}{*}{ Heart failure } & 6,2 & $-1,1$ & $-1,8$ & 0,7 & 151 & 2,0 & 1 & NA & NA & NA & NA & 3 & 1 & 1 & 0 & 1 \\
\hline & NA & NA & NA & NA & NA & NA & NA & NA & NA & NA & NA & NA & NA & NA & NA & NA \\
\hline
\end{tabular}




\section{SUPPLEMENTARY DATA}

Table 1. General data of the whole cohort of patients carrying an IGFIR defect.

Figure 1. Molecular strategy adopted for $I G F I R$ defects diagnosis in the laboratory. SGA: small for gestational age, SRS: Silver-Russell syndrome, MLPA: multiplex ligation-dependent probe amplification. IGF1R defect suspicion was based on the presence of microcephaly and/or elevated IGF-I levels. ,

Figure 2. cDNA sequencing for the patient carrying the NM_000875.4:c.1247+1_1247+2insG variant, responsible for a one-base-pair insertion, leading to a frameshift and premature stop codon (N417EfsX52).

Figure 3. Quantification of ERK phosphorylation calculated as:

[(P-ERKpatient/ERKpatient)/GAPDHpatient] $\quad$ [(P-ERKcontrol/ERKcontrol)/GAPDHcontrol $]. \quad$ WT: wildtype allele. Experiments were repeated from 3 to 6 times for each individual. Error bars represent the standard error of the mean. Del ex1-21 corresponds to Del4 in figure 1 and Del ex20-21 to Del7.

Figure 4: IGF1R cDNA expression in fibroblasts. Primers used:

Igf1R-219-F: ACAGGGATCTCATCAGCTTCAC and Igf1R-219-R: TCCACCATGTTCCAGCTGTT. The amplicon length was $109 \mathrm{bp}$, spanning exons 7 and 8. Del ex1-21 corresponds to Del4 in figure 1 and Del ex20-21 to Del7. 